\title{
ASDesign: A User-Centered Method for the Design of Assistive Technology That Helps Children with Autism Spectrum Disorders Be More Independent in Their Daily Routines
}

\author{
Raquel Cañete *(D) and M. Estela Peralta (D)
}

Citation: Cañete, R.; Peralta, M.E. ASDesign: A User-Centered Method for the Design of Assistive Technology That Helps Children with Autism Spectrum Disorders Be More Independent in Their Daily Routines. Sustainability 2022, 14, 516. https:// doi.org/10.3390/su14010516

Academic Editor: Barbara Motyl

Received: 1 December 2021

Accepted: 28 December 2021

Published: 4 January 2022

Publisher's Note: MDPI stays neutral with regard to jurisdictional claims in published maps and institutional affiliations.

Copyright: (C) 2022 by the authors. Licensee MDPI, Basel, Switzerland. This article is an open access article distributed under the terms and conditions of the Creative Commons Attribution (CC BY) license (https:// creativecommons.org/licenses/by/ $4.0 /)$.
Escuela Politécnica Superior, Departamento de Ingeniería del Diseño, Universidad de Sevilla, 41011 Sevilla, Spain; mperalta1@us.es

* Correspondence: raqcanyaq@alum.us.es

\begin{abstract}
COVID-19 has posed new physical and mental challenges for the population worldwide, establishing social and structural changes in the labor market that could be maintained and implemented permanently. This new reality will require new strategies to improve family and work conciliation, which is especially challenging for families with children suffering from psychological pathologies such as autism spectrum disorder (ASD). These changes have led to more frequent and intense behavioral problems, causing stress, anxiety, and confusion for these children and their families. Thus, the need to have tools that help parents reconcile work with the care of these children, who have low autonomy, is reinforced. This work develops a method for the design of assistive technology and smart products to support children with ASD in following a routine and managing tasks autonomously. In this way, the article analyzes the design problem including the needs and preferences of children with ASD and their parents during confinement in terms of dependence and adaptability; develops a design method for interactive and smart products focused on children with ASD in confinement situations; and validates this method in a case study, in which a robot is developed that makes it easier for children with ASD to follow a routine.
\end{abstract}

Keywords: assistive technology; smart products; autism spectrum disorder; self-managed tasks; confinement periods; inclusive design

\section{Introduction}

COVID-19 has posed new physical and mental challenges for the population worldwide. The confinement and disruption of daily routines have led to a series of psychological consequences that society now has to face. This reality is aggravated in those who suffer from psychological pathologies, such as autism spectrum disorder (ASD). Unpredictable changes in routine can lead to serious difficulties for children with ASD. Their behavioral inflexibility causes significant interference with their behavior in different contexts, even for those at the milder end of the spectrum. Additionally, the difficulties they present in planning and organizing skills cause low self-autonomy and the inability to self-manage.

A survey conducted by the University of Verona and King's College London on how children with ASD are experiencing the COVID-19 pandemic concludes that they "are particularly at risk due to their vulnerability to unpredictable and complex changes" [1]. The results of this study show that the experience of confinement led to more frequent and intense behavioral problems, as the unpredictability of the situation caused stress, anxiety, and confusion for these children.

Additionally, this situation has been particularly complex for parents. The need to work from home, together with the difficulties that their children face to self-manage their day-to-day, has generated stressful situations derived from the disruptive behavior of their children. Planning daily activities and reconciling family life has become a chal- 
lenge. On top of this, we could add the anxiety caused by the difficulty of these children understanding the situation [2].

Despite this, the confinement experience has raised interesting social changes that could be maintained and definitively implemented in daily life, such as teleworking, online education, and intensive or reduced working hours [3-5]. In addition to this, the new trends in automation and Industry 4.0 are leading to new professional roles which are geographically distributed, requiring more responsibility and flexibility. All this will require families and professionals to adopt new strategies to improve family and work reconciliation, a particularly important challenge for families with children with special needs.

Both in periods of confinement and these future contexts, the need for assistive technology is emphasized [6]. Traditional tools (low-tech), although beneficial, can be inflexible and monotonous, leading to a loss of interest on the part of the children. Moreover, they require constant interaction with an adult. In contrast, there are other tools (mid- to hightech) that integrate smart behavior and interactively adapt to the child's development, which favors the evolution of the child. Their dynamic content is more attractive, and they autonomously provide constant instructions, facilitating user independence.

It should be noted that an assistive technology product aimed at people with ASD must be accessible from the physical, cognitive, and sensory dimensions. Currently, the variety of frameworks, methodologies, and tools for design specialized in ASD is scarce. There are general frameworks for universal design [7], design processes for people with special needs, and a series of tools focused on participatory and collaborative design. However, there is no single universal methodology for the design of assistive technology specialized in ASD, and not everything available can be applied to smart products. In addition to this, no methodology has been found in the scientific or technical literature aimed at designing interactive and smart products specialized in ASD for confinement or isolation contexts. The identification of the needs of these children and their families during confinement is essential to be able to make an attractive and useful product. With this goal, the following research question was asked:

How can assistive technology help children with autism and their parents to plan and self-manage their day and thus prevent episodes of stress, anxiety, and frustration for both during periods of confinement?

To answer this question, this work develops the ASDesign method. It is a method for the design of assistive technology and interactive and smart products that supports children with ASD in following a routine and managing tasks autonomously in confinement contexts. Within this scope, confinement is understood as a period in which someone is locked up or confined in a certain place or within limits [8]. It can occur for both desirable causes (teleworking, work-family conciliation, vacations, care of relatives, etc.) and undesirable or unexpected causes (rest or sick leave, health emergency, etc.). This method, based on usercentered design, will facilitate the proposal of mid and high-tech solutions that children can use comfortably and safely while alone and with less frequent parental supervision.

To this end, this work is structured as follows; Section 2 presents a context analysis, which justifies the knowledge contribution of this research, including a market study and the new needs arising from the COVID-19 pandemic. Section 3 shows the methods and materials used for the development of the ASDesign method and develops the proposal in detail. Section 4 validates this method in a case study that includes the design of a robot that allows the configuration and monitoring of a daily routine. Finally, Section 5 discusses the results and main conclusions of this work.

\section{Context Analysis}

The American Psychiatric Association defines ASD as "a complex developmental condition that involves persistent challenges in social interaction, speech, and non-verbal communication, and restricted/repetitive behaviors" [9]. According to Autism Speaks [10], today 1 in 59 children has ASD. There are two fundamental symptoms of autism: 
(i) persistent impairments in communication and social interaction and (ii) restrictive and repetitive patterns of behavior, interests, or activities. The areas where they have the most difficulties are social interaction, imagination, and communication. Therefore, people with ASD tend to isolate themselves and show no interest in others. This is accentuated for those who present communication difficulties due to speech delays or, in some cases, the absence of verbal communication. In turn, they avoid eye contact, as well as physical contact, in addition to having difficulty showing their own emotions and understanding those around them. Their social imagination is limited: they tend to avoid symbolic games and often repeat the same game, or even the same movements, continuously. Sudden changes or disruptions in their daily routine can be a great frustration for them. On top of this, they show limited attention, cannot concentrate on a task for too long, and may exhibit sensory processing disorder.

COVID-19 and lockdown have caused serious difficulties for children with ASD and their families. The limitations of physical space and the transformation of their daily routine (including the disruption of diet and sleep, as well as the interruption of teaching, therapies, and sessions in special centers) are generating a very significant mental and emotional impact [2,11-13]. Although several of these services have been offered online, experts argue that they are less effective than those received in person [14]. In addition to this, it should be noted that the online modality has caused interruptions or cancelations of activities due to technical difficulties or digital poverty in some families $[11,15,16]$. The lack of availability of these resources causes uncooperative and disruptive behavior in children, including periods of anxiety derived from the impossibility of understanding the situation [2]. Fundamentally, the most common consequences have been stress, anxiety, behavioral problems, emotional crises, irritability, obsession, hostility, impulsivity, repetitive behaviors, eating disorders, and insomnia. However, many parents considered satiety one of the biggest problems during the pandemic, stating that there was a "significant reduction in the time children spent with their favorite objects" $[12,17]$. Several factors have accentuated these consequences: (i) age (the younger the child, the more stress the parents suffer) [18,19]; (ii) degree of disorder (children with a higher degree have suffered more stress, as well as their relatives); (iii) disruption of routine (children at the "mild end" of the spectrum who were used to attending school and other activities suffered stronger behavioral disorders than those who were used to staying at home) [19]; (iv) economic situation (the loss of work and onset of economic difficulties have increased stressful situations, since many families could not afford online treatment or lacked the necessary technology to be able to receive it) [18]; (v) health risk factors (homes with high risk could not accommodate specialized professionals at home) [19]; and (vi) cultural aspects [18].

This situation has also been especially difficult for parents due to the need to combine the workday with the care of their children [17]. Many of the tasks and responsibilities that were previously distributed among several agents (teachers, therapists, etc.) have had to be carried out by parents, assuming the different roles without having the necessary knowledge and resources [11-13,16]. Regarding these difficulties, experts have given a series of guidelines to try to reduce stress and frustration $[2,17,20]$, with some of the most common ones as follows:

- Structure daily activities.

- $\quad$ Divide daily activities to establish new routines.

- Use visual tools to help the child understand and self-manage their day.

- Choose the activities that your child prefers.

- Include serious games that help the child improve certain skills.

- Include parents in activities and avoid isolation from the child.

- Maintain contact with schools, therapists, and other children.

- $\quad$ Leave free time.

- $\quad$ Try to give relaxing resources: relaxing space, physical exercise, or sensory stimuli.

- Explain what COVID-19 is in a simple way. 
Most of these guidelines focus on planning the day in a way that helps children follow a clear temporal structure. Despite the efforts made by parents to try to control the situation, they reported the need for more support to preserve their children's mental health, as well as their own $[1,12,18]$. Therefore, experts state that to help children with ASD during these situations, it is essential to focus the research and intervention efforts not only on the child, but also on the development of appropriate support tools for their parents $[12,13,16]$. These tools are part of what we know as assistive technology.

The International Classification of Functioning, Disability, and Health (CIF, WHO, Geneva, Switzerland) defines assistive products and technology as "any product, instrument, equipment, or technology adapted or specially designed to improve the functioning of a person with a disability" [21]. This assistive technology differentiates between "lowtech" (traditional tools and methods that use noninteractive products or do not use energy), "mid-tech", and "high-tech".

The low-tech tools used in language therapies are based on augmentative and alternative communication systems (AAC), based on the use of symbols or images as a form of expression. The most common approach within these systems is the Picture Exchange Communication System (PECS), where users communicate their needs and preferences by exchanging images. Usually, these images and drawings are collected in a book that users carry with them. Specifically, there are several tools to assist in task planning, such as visual task sequences, choice boards, first-after sequences, visual schedules, key phrase symbols, and tags [22]. These tools are typically used at home, schools, and special centers to help children with autism know exactly how the day will evolve and avoid episodes of frustration and emotional breakdowns. There is a wide variety of products available for this purpose in the market.

One of the main drawbacks of conventional tools is that they are very rigid and do not adapt to the evolution of the user's needs. Therefore, mid-tech (with simple electronic elements, such as recorders, e-books, headphones, and visual timers [23]) and high-tech products (with electronic and computerized elements that improve efficiency, speed, and accessibility) implement interactive or intelligent actions with multisensory reinforcements, making the user experience self-adaptive, dynamic, and intuitive. The last group also includes mobile applications such as the Happy Kids Timer Chores App [24] and the Choiceworks App [25] or the emerging field of the development of assistive robots. These collaborators can have very positive effects on the development of social skills of children with ASD; in addition, they have an immediate positive effect on communication skills [26].

The repetitive and predictable behavior of these tools provides a greater sense of security to the child [27]. They can also be easier to understand, as they continuously display instructions and comments. Most children with ASD have been shown to exhibit a clear preference for robots [28]; the game is visually more appealing than individual tasks with parents, therapists, or non-robotic toys. In addition to this, the appearance of robots can stimulate social interaction skills, such as eye contact or communication [27], and can motivate the child to talk, learn, or share interests with others, also improving communication [29]. Finally, they can also help detect and understand emotions and social behaviors [30]. To this we must add that many of them do not require the child to own a phone or tablet, avoiding the continuous supervision of the parents. Examples of these robots are Leka [31] and Kaspar [32].

One of the main disadvantages of these products is their affordability; due to their high price, they are mostly used as a professional tool in therapy. On the other hand, most robots focus on improving social skills, and as stated by the Japan Society of Instrument and Control Engineers (SICE, Chiyoda City, Japan) (2019), the development of robots aimed at monitoring the daily routine of children with autism to integrate into real society remains unexplored [33].

Therefore, the line of research in which the ASDesign method is developed is an incipient and interesting area of work that contributes to improving the well-being of children with ASD and their families during confinement periods. 


\section{Materials and Methods}

This section describes the proposal of the ASDesign method and its application context; for its development, the following stages were carried out, which will be explained in the following sub-sections:

- $\quad$ User analysis, context of use, and definition of needs (Section 3.1). Development of the ASD_T1 design module of the method.

- Definition of functional and technical requirements as well as design parameters of assistive technology (Section 3.2). Development of the ASD_T2 and ASD_T3 design modules of the method.

- $\quad$ Definition of the design process for ASDesign and application requirements (Section 3.3)

Due to the fact that the definition of the target user of ASDesign is complex (parents and children with autism in a domestic context in periods of confinement), it was established that the method would include a set of tools or modules, called "ASD_Tnum modules", that would facilitate decision-making throughout the design project. These modules, as will be explained later in the following subsections, allow special needs to be selected and make it easier to establish their relationship with functional requirements and optimal design variables.

\subsection{User Analysis and Definition of Needs}

Every product design process begins with the analysis of the user's needs. In the design problem solved by the ASDesign method, two groups of needs are identified: (1) the basic needs of ASD and (2) the specific needs derived from confinement.

First, to define basic needs, it is necessary to take into account the severity of children's difficulties, currently classified into three levels of autism [9]. This work focused on the mildest level of the spectrum (level 1). Children in this range may have deficiencies in social communication if they do not have sufficient support, and have little interest (and difficulty) in initiating social interactions, in which they also show atypical or insufficient responses. On the other hand, behavioral inflexibility generates significant disorders in their behavior in different contexts. They have difficulty alternating activities, organizing, and planning, which entails little autonomy and independence. Table 1 shows the basic ASD needs included in the ASDesign method.

Table 1. Definition of basic ASD needs (BN).

\begin{tabular}{ll}
\hline \multicolumn{1}{c}{ Basic Needs of ASD } & \multicolumn{1}{c}{ Objectives } \\
\hline $\begin{array}{l}\text { Development, maintenance, and understanding } \\
\text { of relationships }\end{array}$ & Adapt behavior to different contexts \\
\hline Attention & Obtain and maintain the child's attention \\
\hline \multirow{2}{*}{ Emotional reciprocity } & Express preferences and ideas \\
\cline { 2 - 2 } & Initiate and maintain social interactions \\
\hline \multirow{2}{*}{ Restrictive and repetitive patterns of behavior } & Disproportionate and repetitive gestures \\
\cline { 2 - 2 } & Small variety of interests \\
\cline { 2 - 2 } & Inflexibility in routines \\
\cline { 2 - 2 } & Stress and frustration to changes \\
\hline Environment and social awareness & Social and environmental awareness \\
\hline Motivation & Motivation and goal setting \\
\hline Disruptive behavior & Behavior management \\
\hline
\end{tabular}

As a second step, the definition of needs during periods of confinement was carried out through three phases: (1) analysis of research in the socio-health, psychological, and 
sociological areas, (2) interviews with professionals, and (3) analysis of the behavior of the target user through a questionnaire.

The first phase included an analysis of the state of the art and selection of different statistical studies and research carried out during the confinement period; in general, these studies were based on interviews with parents of children with ASD and professionals in the areas of medicine and psychology [1,2,11-20]. This phase made it possible to identify the greatest difficulties that families experienced during the pandemic, psychosocial risk factors, and main consequences, in addition to a set of expert recommendations to reduce impact. To complete the above information, as a second phase, a semi-structured interview was conducted with a pediatrician from an ASD association. The objective was to collect the specific experiences and intervention activities carried out by specialized centers after the COVID-19 interruption.

As a result of technical analyses 1 and 2, a first classification of the most significant difficulties was obtained, which was later translated into needs for the ASDesign method:

- $\quad$ The attention required by the child.

- Combine work and childcare.

- Calm the child in times of stress.

- Getting the child to focus on an activity or product.

- Explaining the pandemic situation to the child.

- $\quad$ Structuring or planning daily activities.

- Getting the child to do certain activities he or she does not like.

On the other hand, and with the aim of gaining a deeper understanding of the experience of the target user in the periods of confinement, the user's behavior was analyzed through a questionnaire aimed at parents of children with ASD. It was answered by 51 subjects. Most of the children represented in this research are under 10 years old (62\%), and most of them received online support from professionals (61\%). The questionnaire included three blocks of questions to obtain different information:

- $\quad$ BLOCK 1: Composed of 10 questions about the situation of children with ASD during confinement. It made it possible to identify the greatest difficulties for parents regarding their children and the order of priority of these demands.

- $\quad$ BLOCK 2: Composed of 6 questions on the use of low, medium, and high technology tools. The result was the identification of tools used to plan the routine, the frequency of use, and the evaluation of usability. On top of this, it explored whether the tools were interactive (mid to high-tech), collecting the reasons for preference of use over conventional tools (low-tech).

- $\quad$ BLOCK 3: Composed of 3 questions about purchasing behavior. It led to the aspects that influence the purchasing decision, as well as the priorities of parents when deciding on a product or tool for their children.

In the first block, the results show that $19 \%$ of parents did not consider confinement a difficult period for their children, but for themselves. However, on the other hand, this percentage of users argues that one of the biggest difficulties had been to calm their child in emotional crises. That is, parents agree that the confinement was worse for them; however, they verify the existence of emotional crises in their children in this period. On top of this, this block showed that only $29 \%$ of the parents combined work and the care of the child ( $49 \%$ had to dedicate themselves exclusively to the care of the child, $16 \%$ had to leave home to work onsite, and $6 \%$ worked from home while someone else took care of their child). This information is consistent with the conclusions of Phase 1: needs analysis (statistical studies and research published in the scientific literature).

Regarding the identification and prioritization of difficulties, the questionnaire led to the classification of the different demands of the children according to the stress they generated (Table 2). The hierarchy was carried out using a weighting factor to synthesize the results and establish the order of priority of the specific needs of the confinement (CNi). The weighting factor was established following these steps: (I) participants ranked the 
confinement needs (CNi) from most to least difficult (Positions P1-7); (II) the frequency for how many times each confinement need $(\mathrm{CNx})$ appeared in each position $(\mathrm{Pj})$ was established (Fxj); (III) all frequencies were divided between the number of responses I; (IV) the resulting value for each position ( $\mathrm{Fxj} / \mathrm{R})$ was multiplied by a scaling factor according to the position $(\mathrm{Pj})(\mathrm{P} 1=7, \mathrm{P} 2=6, \mathrm{P} 3=5, \mathrm{P} 4=4, \mathrm{P} 5=3, \mathrm{P} 6=2, \mathrm{P} 7=1)$; (V) the results were recorded as the weighting factors.

Table 2. Specific needs of the confinement (CNi).

\begin{tabular}{llc}
\hline \multicolumn{2}{l}{ Specific Needs of Confinement-Priority Order } & Weighting Factor \\
\hline N1 & Maintain the child's attention and interest in a product or activity. & 4.78 \\
\hline N2 & Calm my child down in moments of stress. & 4.45 \\
\hline N3 & The attention required by the child. & 4.13 \\
\hline N4 & Getting the child to do tasks that he/she does not like. & 3.98 \\
\hline N5 & Structure and plan daily activities. & 3.66 \\
\hline N6 & Explain the pandemic situation to the child. & 3.57 \\
\hline N7 & Combine the workday with the care of the child. & 3.36 \\
\hline
\end{tabular}

The answers in block 2 (regarding the tools used and their functionality) showed that those of low technology (or traditional) were the most used and most valued, the most popular ones being: the visual task sequences, the visual daily sequences, the FirstThen activities boards, and the choice boards [34]. Parents also added reward panels as a useful tool. Furthermore, only $22 \%$ of the families frequently used high-tech in the form of mobile applications to replace conventional tools. Regarding the evaluation of the functionality of the tools, the following design deficiencies were identified: lack of personalization (inserting desired activities) (with 25\%), the required supervision (25\%), loss of interest of the child (10\%), and the need to have a mobile phone for its use (25\%). Finally, only $1 / 51$ children used high technology in the form of a robot or a similar product during confinement.

Lastly, block 3 on purchasing behavior identified the design and functional requirements that influence the choice of low, medium, and high technology: have visual support $(88 \%)$ and hearing support $(94 \%)$, be easily transportable $(98 \%)$, allow you to schedule activities in advance (90\%), and allow the child to choose the activities at the time of use $(94 \%)$. On a second level, to the given aspects, some parents added as priorities having different levels of difficulty, being affordable (price), and being intuitive.

Once the three phases of the analysis of the target user were completed, the relationship between the specific needs of confinement (CNi) (Table 2) and the basic needs of ASD (BN) (Table 1) [9] was established. This made it possible to determine which basic needs of the disorder should be worked on for each specific need of confinement. The correct use of cross-relationships ensures that the product design is properly adapted to the complete needs and characteristics of these children. To make it easier for the design team to select cross-needs, the module ASD_T1 was developed (Table 3).

Once the $\mathrm{CNi}$ (specific needs of confinement) are known, the design team can easily identify the basic needs of ASD that must be prioritized in the design of the product.

It should be noted that although the specific needs N2 (Calm my child down in moments of stress) and N6 (Explain the pandemic situation to the child) have been included in the ASDesign method, they are too complex to solve with a product. Specifically, as the questionnaire showed, the last stage of the emotional crisis is the most difficult challenge for parents, when the child is already under a lot of stress. Trying to implement a solution at that point is extremely difficult. Instead, the right thing to do would be to identify the causes that led to the crisis in order to avoid the episode in the future. This is grounded on the concept of Positive Behavioral Support of proactive approach [35] and functional analysis, strategies that work on self-regulation to improve independence and autonomy. 
Table 3. ASD_T1. Relationship between basic ASD (BN) and confinement-specific (CN) needs.

\begin{tabular}{|c|c|c|c|c|c|c|c|c|}
\hline \multirow{2}{*}{\multicolumn{2}{|c|}{ Basic Needs of ASD }} & \multicolumn{7}{|c|}{ Specific Needs of Confinement } \\
\hline & & \multirow{2}{*}{$\frac{\text { N1 }}{\mathrm{X}}$} & \multirow{2}{*}{$\frac{\text { N2 }}{x}$} & \multirow{2}{*}{$\frac{\text { N3 }}{X}$} & \multirow{2}{*}{$\frac{\mathrm{N} 4}{\mathrm{X}}$} & \multirow{2}{*}{$\frac{\text { N5 }}{X}$} & \multirow{2}{*}{$\frac{\text { N6 }}{X}$} & \multirow{2}{*}{$\begin{array}{r}\text { N7 } \\
X\end{array}$} \\
\hline $\begin{array}{l}\text { Development, maintenance, and } \\
\text { understanding of relationships }\end{array}$ & Adapt behavior to different contexts & & & & & & & \\
\hline Attention & Obtain and maintain the child's attention & $x$ & $x$ & $x$ & $x$ & $x$ & $x$ & $x$ \\
\hline \multirow{2}{*}{ Emotional reciprocity } & Express preferences and ideas & $x$ & $x$ & $x$ & $x$ & $x$ & $x$ & $x$ \\
\hline & Initiate and maintain social interactions & & $x$ & $x$ & $x$ & $x$ & $x$ & $x$ \\
\hline \multirow{4}{*}{$\begin{array}{l}\text { Restrictive and repetitive } \\
\text { patterns of behavior }\end{array}$} & Disproportionate and repetitive gestures & $x$ & $x$ & $x$ & $x$ & $x$ & & $x$ \\
\hline & Small variety of interests & $x$ & & $x$ & & $x$ & & $x$ \\
\hline & Inflexibility in routines & $x$ & $X$ & $x$ & $x$ & $x$ & & $x$ \\
\hline & Stress and frustration to changes & $x$ & $x$ & $x$ & $x$ & $x$ & & $x$ \\
\hline $\begin{array}{l}\text { Environment and social } \\
\text { awareness }\end{array}$ & Social and environmental awareness & $x$ & $x$ & $x$ & $x$ & $x$ & $x$ & $x$ \\
\hline Motivation & Motivation and goal setting & $x$ & & $X$ & & $x$ & & $x$ \\
\hline Disruptive behavior & Behavior management & & $X$ & $x$ & $x$ & $x$ & & $x$ \\
\hline
\end{tabular}

\subsection{Definition of Functional Requirements and Design Parameters}

The definition of crossed needs allows designers to translate the areas that we intend to work with or support using technology (signs, symptoms, and difficulties of ASD) into design strategies: (1) functional requirements and (2) design parameters.

First, functional requirements define the functions of the system (technology or components). They specify the behavior between inputs and outputs of resources (information, energy, materials, or space), which are exchanged in the user-product environment. In the design process, it is necessary to have a correct translation of needs into functional requirements. In the ASDesign proposal, for all the crossed relationships of the module ASD_T1 $(\mathrm{BN}+\mathrm{CN})$, the functional requirements (FR) to be taken into account in the product design were identified. In addition to this, non-functional or quality requirements (NFR) were defined; these refer to the properties of the product (usability, safety, comfort, adaptability, performance, and transportability). Finally, the smart requirements (SR) for the design of high-tech products were identified. To facilitate the translation of needs $(\mathrm{BN}+\mathrm{CN})$ into requirements (FR, NFR, and SR), the module ASD_T2 was developed. Figure 1 shows the structure and its purpose and can be checked in detail in Annex I.

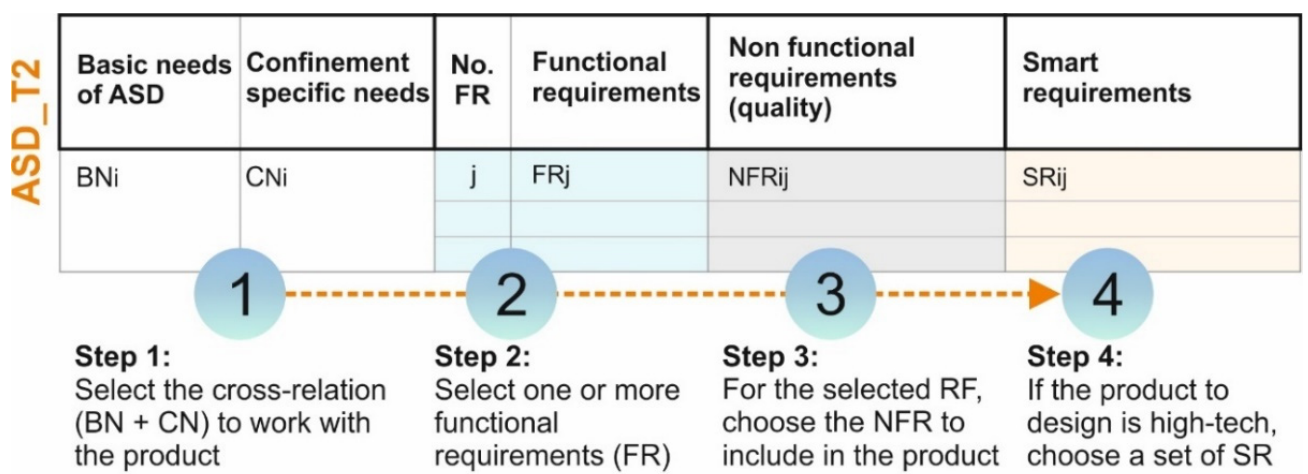

Figure 1. ASD_T2 for the translation of needs (N) into functional requirements (FR).

As a second step, and derived from the relationship between crossed needs (BN + IN)i and functional requirements (FRj, NFRij and SRij), the design parameters (DP) are identified, being the specifications and constraints required in the conceptual and detail design phases 
to develop the best solution. The definition of design parameters in the ASDesign method was carried out taking into account the special physical, sensory, cognitive, and social characteristics of children with ASD. The definition of design parameters consisted of four phases:

i. An exhaustive review of the scientific and technical literature and the latest research on products aimed at children with ASD [36-40].

ii. Analysis of interactive products [41-47] and robots for children with ASD [48-51].

iii. Market research focused on children with disabilities and developmental disorders [52,53].

iv. Compilation and synthesis of the results of a semi-structured interview conducted with a specialist doctor belonging to an association for children with ASD. Specifically, the interview concluded the routines, tools, methodologies, and other elements that are used in this type of association to maintain the attention and motivation of the children when following a sequence of activities. Most of these proposals referred to conventional methods and low-tech products.

The four previous activities made it possible to identify guidelines for the design (DPjk) and constraints (DCjk) of medium- and high-tech products for these children. To facilitate the selection of DPs, module ASD_T3 was developed. Figure 2 shows the structure of the module and its purpose and can be checked in detail in Annex II of the work.

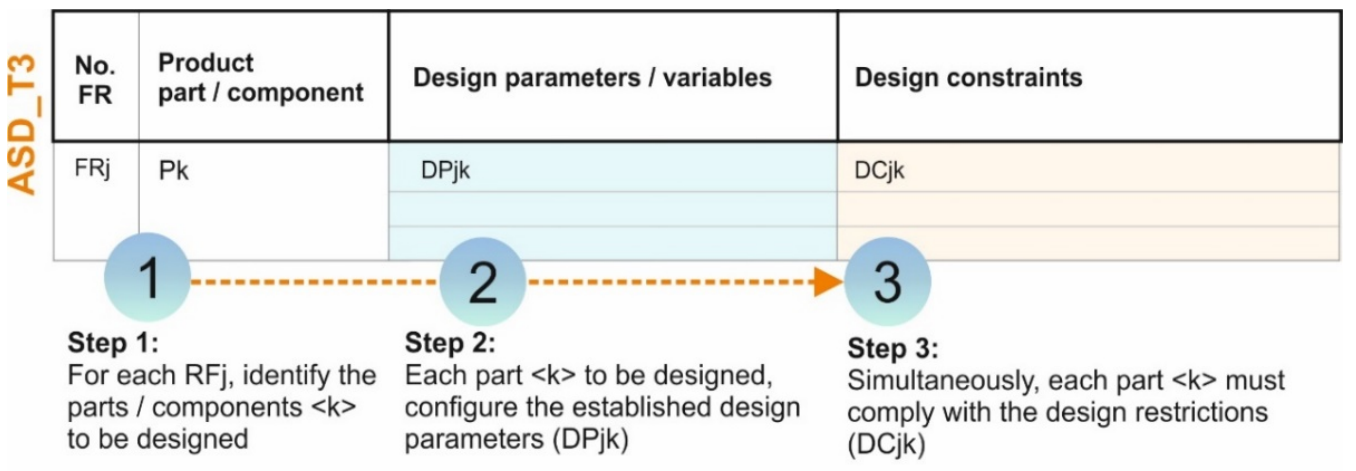

Figure 2. ASD_T3. Design parameters of robots for children with ASD.

Although the module ASD_T3 includes a complete set of DPs, in the conceptual design phase, it is important to take into account the interdisciplinarity and collaboration between different areas. It will be indispensable, in addition to considering appropriate design strategies, to consider the theories, practices, and experiences existing in clinical and educational settings. This is the strategic key to achieving technology-enhanced interventions for users with ASD [54]. Therefore, to make the design project successful, it will be important to use creative techniques (interviews, questionnaires, workshops, research activities, etc.) [55] that allow the integration of different disciplines, such as engineering, psychology, medicine, or education.

\subsection{ASDesign Method}

This section explains the ASDesign method in detail, specifically the applicability and steps to follow. It should be noted that the modules ASD_T1 (cross-relationships between ASD needs and special confinement needs), ASD_T2 (functional requirements), and ASD_T3 (design parameters) are the three basic tools of the method. These tools will be used throughout the design process of assistive products (medium or high technology) as facilitators in decision-making.

\subsubsection{Scope of the ASDesign Method}

ASDesign is a user-centered design method; it is applicable in the development of assistive technology, in the form of interactive and smart products to support children with 
ASD in following a routine and managing tasks autonomously. The technology designed with this method can be used in periods of confinement; in addition, children can configure it comfortably and safely (and supervised by parents). In the ASDesign method, the term "confinement" is understood as a period in which someone is locked up or confined in a certain place or within limits [8]; this can be due to desirable reasons (teleworking, workfamily reconciliation, vacations, etc.) and undesirable or unexpected reasons (rest or leave, illness, health emergency, etc.).

\subsubsection{ASDesign Process}

Figure 3 sets out the flow chart of the main phases to follow. These phases are not strictly linear. Iteration between stages 5, 6, and 7 will allow the necessary adjustments to be made to design decision-making throughout the entire process.

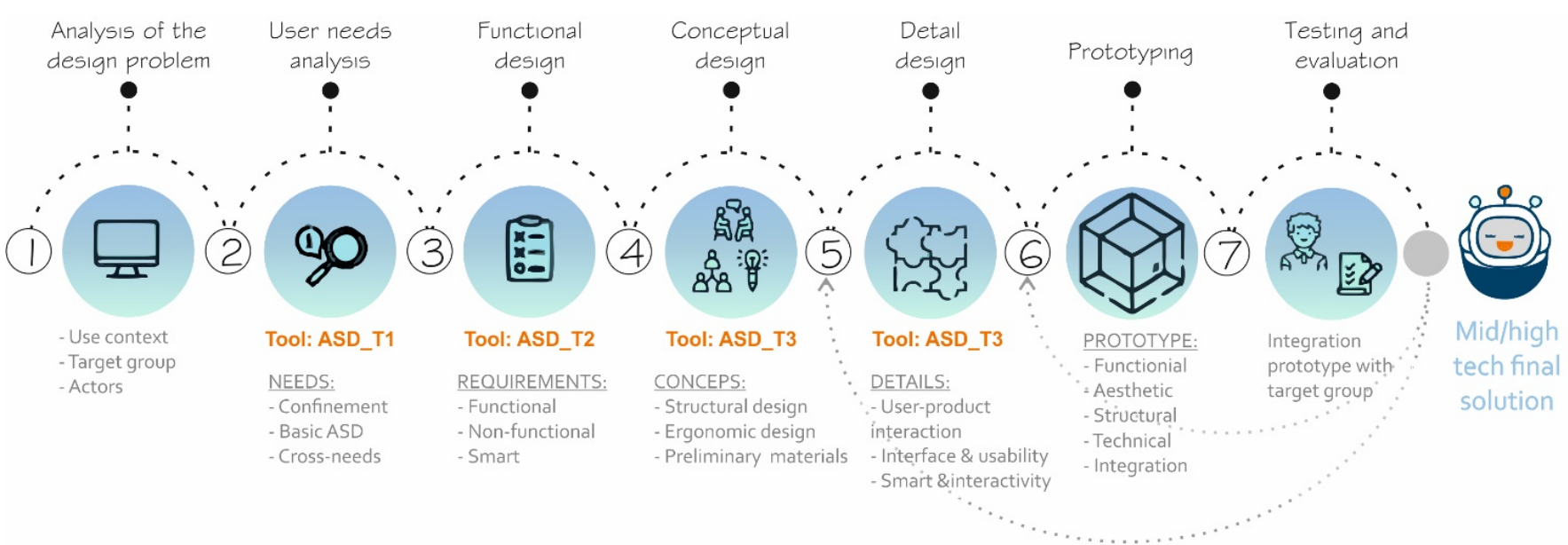

Figure 3. Stages of the proposed method.

Phase 1. Analysis of the design problem: Phase 1 analyzes the design problem, which includes: (1) definition of the characteristics of the context of use (home, therapy, school, indoor or outdoor environments); (2) the target user (ASD picture, degree of ASD to be worked with [9], and the main signs and symptoms to be improved with the product); and (3) the actors involved in the interaction (child with ASD, therapist, parents, other typically developing children, etc.).

Phase 2. User needs analysis: Identification of cross-needs. Once the design problem has been defined, the $\mathrm{CNi}$ needs are selected, relating to the difficulties of confinement (Table 2). These are then related to the basic needs of ASd (BNi) (Table 1). Using module ASD_T1, cross-relationships (CNi + BNi) are identified (see Table 3, Section 3.1), which will ensure that the product is correctly adapted to the target user.

Phase 3. Functional design: Identification of functional requirements. Crossed needs $(\mathrm{CNi}+\mathrm{BNi})$ are translated into product requirements. In this way, and provided by the tool ASD_T2 (see Figure 1 and Annex I), the Functional Requirements (FRj), Non-Functional Requirements (NFRij), and Smart Requirements (SRij) are obtained according to the needs to be solved. The product's requirements should serve as the basis for the design of the different alternatives of the product.

Phase 4. Conceptual design: Conceptual design includes the development and selection of design alternatives. To facilitate the proposal of appropriate solutions, and grounded on the tool ASD_T3 (see Figure 2, Section 3.2 and Annex II), the PDjk design parameters most in line with the functional, non-functional, and smart requirements specified in Phase 3 are identified. The conceptual design phase must achieve the following goals in product design:

- Structural design: Proposal of the structure of the product and its components. 
- Ergonomic design (safety and comfort): An anthropometric, biomechanical, and cognitive study of the child population to ensure the correct adaptation of the product to the user.

- Preliminary selection of materials: Study and selection of materials for the perceptual and sensory adaptability of the product to the user with ASD. In addition, they must ensure the physical and environmental integrity of the product.

Phase 5. Detail design: Once the optimal alternative is selected, the detail design will be finalized, including the following goals:

- User-product interaction design: Development of product states and game modes.

- Interface design and usability analysis: Development of the information exchange system between user and product.

- Design of smart and interactive properties: Development and programming of the intelligent and interactive system.

Phase 6. Prototyping: To validate the design and functions of the technology, different prototypes must be developed:

- Functional prototype: Validates usability in terms of efficiency (goal scope and needs), effectiveness (usage times, usage errors, mental and physical load of the user), and satisfaction (ease of learning, attraction, motivation, attention fixation, ease of recall) in user-product interaction.

- Prototype of aesthetic-formal design (look and feel): Validates the aesthetics and physical and cognitive adaptability (perceptive and sensory) of the design.

- Structural prototype: Validates geometric concordance, shape, and assemblies.

- Technical prototype: Validates the technical feasibility of the solution.

- Integration prototype: A final prototype that integrates the above aspects and aims to be tested with the end-user.

Phase 7. Testing and evaluation: Using the integration prototype of Phase 6 , a test is carried out with the target group; this must be composed of children with ASD, children with typical development, and the rest of the users (parents, psychotherapists, and other agents if they exist). It is recommended to prepare a list of assumptions in advance to validate during the test. The results will be useful for the improvement or redesign of the final solution.

\section{Case Study: The Robot Pepe}

This section applies the ASDesign method with the aim of validating and verifying the proposal. Thus, the robot "Pepe", a high-tech assistive product to support children with ASD to improve the independence of their daily tasks, is designed. Pepe's design made it possible to verify the suitability of the ASDesign method and its applicability to any design project. In addition, the on-site testing with the target user validated the tools ASD_T1, ASD_T2, and ASD_T3 and their suitability to the scope of the method. The following sections summarize the design process and the most representative results.

\subsection{Phases 1, 2, and 3: Context Analysis, Definition of Needs, and Functional Design}

As discussed in Section 3.3, the design problem is defined in the first phase of the ASDesign method. For this case study of the robot Pepe, the following aspects were considered:

(1) Context of use: Domestic, for which an interactive and smart product in the form of a robot is developed for children with ASD. The robot helps to create and follow a routine, improving self-autonomy. The goal is for children to be more independent of their parents in times of confinement.

(2) Definition of the target user: Children with ASD level 1 (mild end of the spectrum) [9]. They have verbal communication skills and can attend schools with typically developing children.

(3) Actors participating in the interaction: Child or child with ASD and their parents (the therapist is not present). 
Once the design problem was defined, in Phase 2 the specific confinement needs (CN) to be solved were selected (see Table 2, Section 3.1). Taking into account that a robot presents high possibilities of customization, as well as self-adaptation to the context and the user, the following CN were selected: N1, N3, N4, N5, and N7, with N2 and N6 being discarded. As discussed in Section 3.1 and according to the principles of the Positive Behavioral Support Methodology [35], although N2 (calming the child in times of stress) is one of the most difficult demands for parents, it is considered important to pay attention to the causes of the problem, that is, to the needs N1, N3, N4, N5, and N7. When these are addressed properly, it is possible to prevent the onset of the crisis. On the other hand, N6 (explain the situation of confinement to the child) is discarded, as it needs to be worked with a completely different approach to the rest of the needs.

Lastly, the specific needs of confinement were related to the basic needs of ASD using module ASD_T1 (Table 3, Section 3.1). In the case study, all the basic needs of ASD were taken into account. These are focused on improving (I) the development, maintenance, and understanding of relationships, (II) attention, (III) emotional reciprocity, (IV) restrictive patterns of behavior, (V), environment and social awareness, (VI) motivation, and (VII) disruptive behavior.

Once the crossed needs to be solved by the Pepe robot were defined, the functional design (Phase 3) was carried out using module ASD_T2 (see Figure 1 or consult Annex I). The tool facilitates the translation of needs $(B N+C N)$ into requirements (FRj, NFRij, and SRij). In this case, the functional requirements RF1-18 were taken into account (see columns 2, 3, 4, and 5 in Annex I).

\subsection{Phase 4: Conceptual Design: Ideation, Generation of Alternatives, and Preliminary Solution}

The ASDesign method takes an interdisciplinary approach in the ideation phase. To do this, the creative process of the Pepe robot was divided into two phases: (1) semistructured interview with a specialist in therapy and early care and (2) an interdisciplinary ideation workshop.

The semi-structured interview was conducted with a specialist doctor who belongs to an association for children with ASD. The conclusions obtained from the previous interview (see Section 3.2) were considered and redesigned as interactive and smart in the Pepe robot. In addition, a series of "expert recommendations" were obtained from the interview and later used in the ideation workshop.

As a second phase, in the interdisciplinary ideation workshop, different proposals for the potential product were developed. Idea generation techniques-brief icebreaker ideation activity and divergent thinking (brainwriting diagram) [55]—were applied. Three professionals participated in the workshop, belonging to the areas of product design, psychology, and education. Starting from a set of previously defined [FR j, NFRij, SRij] (see ASD_T2, Annex I), and taking 2 random design parameters (ASD_T3, Annex II) and 1 expert recommendation (see Section 3.1 and Figure 2), participants generated different design ideas. The inclusion of expert recommendations allowed all of these ideas to be aligned with the context, user, and scope of the design. Finally, they were asked to choose a set [FRj, NFRij, SRij, DPjk] and draw or describe a robot design solution. Figure 4 shows the experience of the workshop.

With the results of the semi-structured interview and the interdisciplinary workshop, seven alternatives to robot design were generated. They were then analyzed considering the design parameters of module ASD_T3 (see Figure 2 and Annex II). All alternatives (Figure 5) were designed not only as an AT product but also as a toy, meaning that technology, in addition to improving, developing, and working on certain skills of the child, is also fun, safe, age-appropriate, and attractive for the user. Therefore, alternative 4 presented better results, thus being the final solution. 

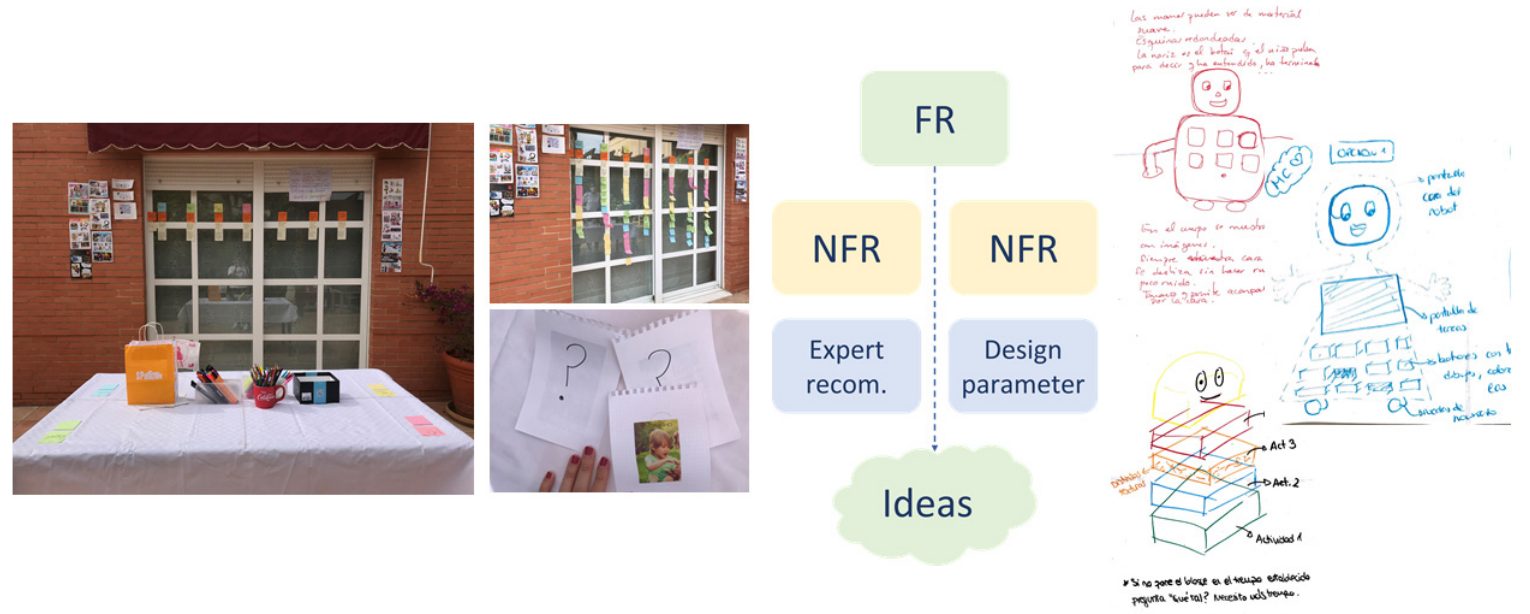

Figure 4. Interdisciplinary ideation workshop.

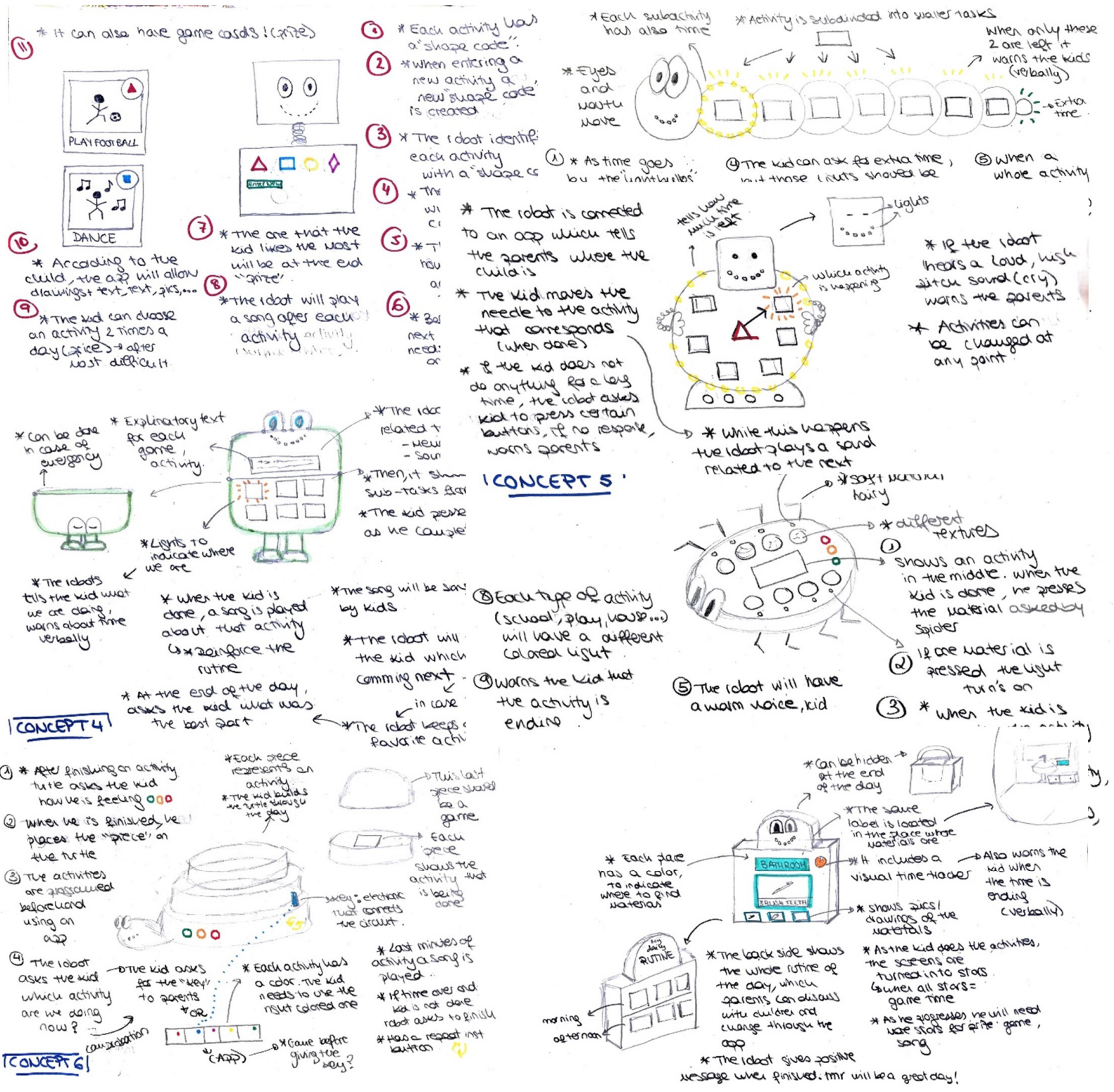

Figure 5. Generation of design alternatives. 
As indicated in Phase 4 of the method, for the selected alternative (see design), the ergonomic design and the preliminary choice of materials were developed using the tool ASD_T3 (see Figure 2 and Annex II). The Pepe robot consists of a structure $40 \mathrm{~cm}$ high and $25 \mathrm{~cm}$ wide. It has four wheels at the bottom that allow it to be easily turned around; in addition, the upper semi-cylinder can be hidden. Some physical elements are elastic, allowing tangibility and mobility of elements. It was designed with a small size to avoid intimidation and also to facilitate manipulation by the child. It is made up of simple geometric shapes to avoid frustration. Pepe has an identity that is easy to understand for a child with ASD: includes an anthropomorphic design (eyes, mouth, and arms) with interactive expressions of emotions. The idea behind giving it a "humanoid" appearance is grounded on the thought that interacting with robots that have "humanoid" elements and interaction features might help children with ASD with their social and communication skills, as well as to maintain attention [26]. In addition, identity makes the child see the product as a playmate (and not as a supervisor); this will create a strong bond between the two and encourage the child to use it with a playful attitude.

As the ASDesign methodology indicates, one of the most important features in smart products is perceptual and sensory stimuli. To achieve a correct adaptation, Pepe includes traditional (low-tech) and computational (high-tech) elements; the objective is to create a product flexible to the user's development but adapted to their sensory characteristics. The low-high tech combination is supported by Mikael Wiberg's approach to "material movement" [56]. Therefore, those elements of traditional tools (low-technology) that are suitable for the user and the satisfaction of their needs were integrated with the ICT and electronic elements, thus configuring the design of the robot. Regarding visual reinforcements, Pepe includes 7 screens that show drawings, images, or text, depending on the child's skills and the game. Compared to conventional tools, including messages through ICT (information and communications technology), elements make the product more adaptable and flexible (both in terms of content and in the way it is presented). In addition to this, Pepe includes a set of physical interaction elements (pushbuttons and sliders). Touch screens were discarded because of the need for tangibility and materiality in the product. These types of physical elements can be manufactured with different textures and materials that create a multisensory experience (greater comfort, acceptability, and agreeability in the task according to the basic needs of the ASD); in addition, they facilitate interaction by involving varied movements of fine (sliding, squeezing, pressing, holding, grasping, gripping, clamping, turning) and gross (dragging and turning) motor skills. The design of low-tech elements is based on the conventional tools used in therapies, such as: (1) having arrows that the child can move and point to different scenes that help him stay focused, and visually understand the next task or predict the next information; or (2) the fact that Pepe's head (semi-cylinder top) can hide, embedding the "Turtle Tool" [22] commonly used to teach children with ASD that, in times of crisis, it is important to disconnect and think before reacting impulsively.

Lastly, the correct selection of materials allows the robot to adapt to the sensory needs of the child, where the materials were prioritized according to the characteristics of their surface (texture, color, and brightness) avoiding the use of reflective materials; pastel colors were prioritized (see Figure 6). Tactile stimuli are very beneficial in capturing the child's attention and making him enjoy a certain product. In addition, according to the design parameters of the ASDesign method (see Annex II), it is also advisable to include soft, non-toxic materials, which are suitable for outdoor environments. Therefore, the selected materials were as follows: PET of different textures (smooth, bubbles, metallic), felt, curl, nylon, and foam. 

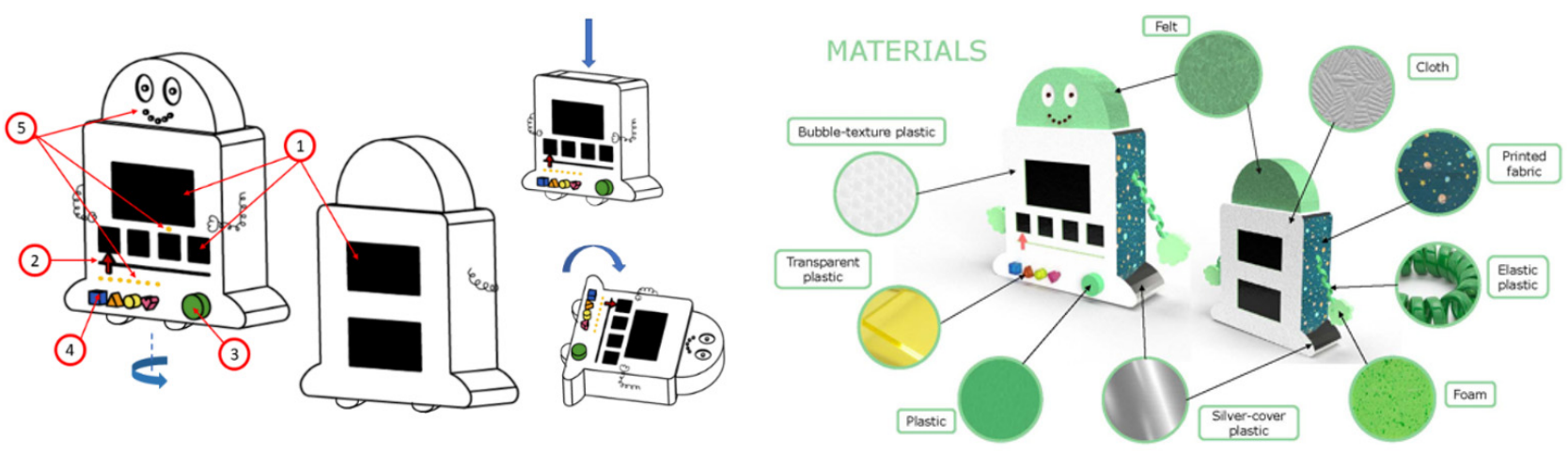

Figure 6. Preliminary design of the Pepe robot.

\subsection{Phase 5: Detail Design}

Following Phase 5 of ASDesign, (1) the design of the user-product interaction (in this case robot states and game modes), (2) the design of the interface and usability analysis (information-action exchange system between user and robot), and (3) design of the intelligent and interactive properties of the product were carried out.

Pepe is a robot designed to help follow a routine previously planned by the parents and the robot itself. It is designed to guide the child throughout the day and work on needs (N1, N3, N4, N5, and N7), making use of different activities based on gamification. In this way, Pepe suggests a routine to parents for the next day, including main activities and subtasks based on the child's performance with the product itself. It is able to record which activities the child prefers, which are more difficult, and which ones he/she has already learned (depending on how long they take the child). On top of this, it can change the level of support given to the child, adding and removing elements progressively. Scheduled activities are presented throughout the day using the different interface screens; the child will interact with the robot through different interface elements (see Figure 6, elements 2, 3, and 4). Pepe includes voice, sounds, music, lights, and textures as supporting elements to make the experience more engaging and interactive. The main goal is to keep the child involved in the different activities by creating a reward system and making a game out of the routine (gamification). The robot and its functionality will evolve along with the child as he/she progresses in the development of self-autonomy. These strategies are based on the Positive Behavioral Support methodology [35]. Figure 7 shows the functions and stages of the robot.

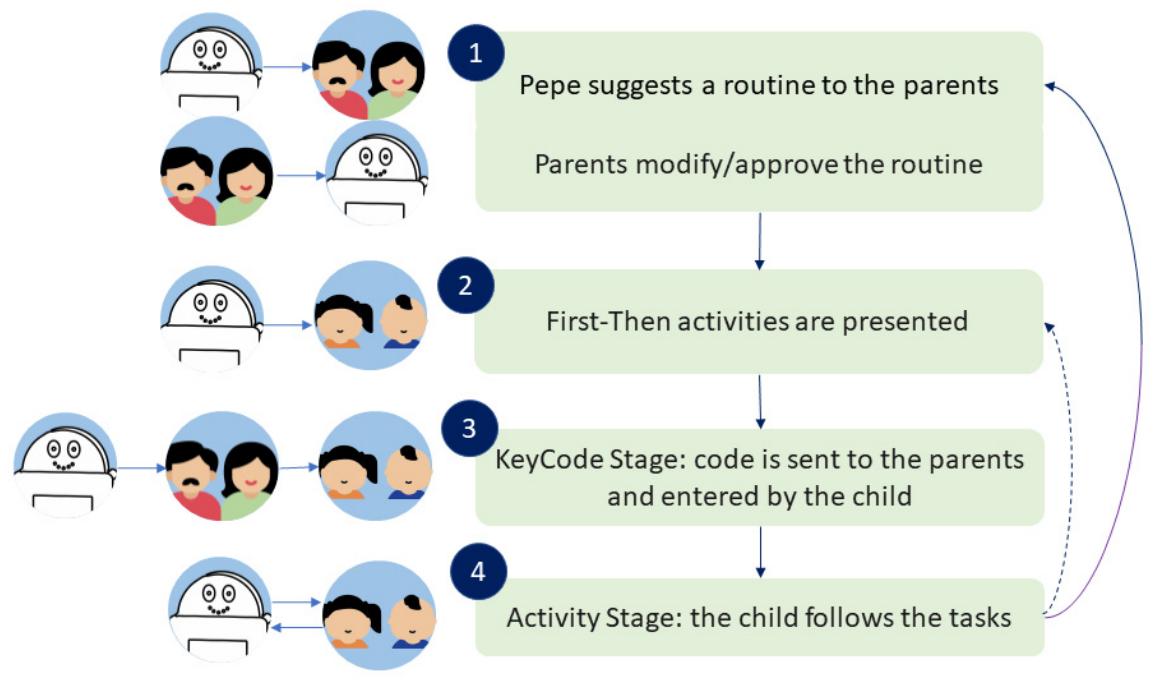

Figure 7. Functionality of the Pepe robot. Main stages. 
As shown in Figure 7, the design has four main stages that allow for creating a dialogue between parents, child, and robot. These stages are described below:

1. Stage 1. Establishment and approval of the routine: The robot suggests a possible routine to parents for the next day. Since the robot can record and interpret the child's data (time spent on each activity, how the activity made him feel, and which tasks proved more difficult), Pepe suggests an adapted routine. This means that depending on the child's performance, he/she will add or remove tasks, if necessary, combine the activities that the child likes or dislikes in the correct order, add games to help the child memorize the tasks, and change the images according to the level of difficulty in interpretation (going from $<$ images $>$ to $<$ pictograms $>$ to $<$ text $>$ ). Parents, through a mobile application, will be able to modify and approve the routine. At first, Pepe will have a more rigid approach (the control of the activity depends on the parents); however, as the child progresses, Pepe will be more flexible and allow the child to choose more activities, gradually giving him more self-autonomy (see Figure 8a).

2. Stage 2. Presentation of First-Then activities: The robot gives the child a "welcome message" verbally and says it is time to start with the activities. It asks the child to turn it around. The back will always show which activity is going to be done first and which one is going to be done next. The robot will ask the child what activity is going to be performed next and ask for the "KeyCode" of the next activity (see Figure 8b).

3. State 3. Identification and introduction of the activity code: The "KeyCode" consists of a sequence of "shapes" that is connected to each activity. This code will be displayed in the app (to parents). Once the child has identified which activity is going to be performed "now" (first screen on the back), he/she must find out the code and enter it into the robot. The child enters the sequence using the SHAPE buttons on the robot to "unlock" the next activity. This stage will serve as a checkpoint (see Figure 8c).

4. Stage 4. Activity and subtasks: When Pepe detects the correct code, the screens display the main activity (large) and subtasks (small), along with lights on the timeline. The robot warns the child verbally about the beginning of the activity and indicates the first subtask. The first subtask will light up. As time passes, the lights on the timeline will begin to turn off. When the timeline approaches the next subtask, the robot will tell the child that it is time to move on to the next one. As the child finishes with one subtask, he or she moves the arrow to the next one (which will light up) and will press the YES button. When the YES button is pressed, Pepe verbally congratulates the child, and a star will appear in the completed subtask. The stars will be recorded in the app for parents and children to see. A certain number of stars will imply a reward. The app also informs parents of the child's progress on tasks and subtasks (see Figure 8d).
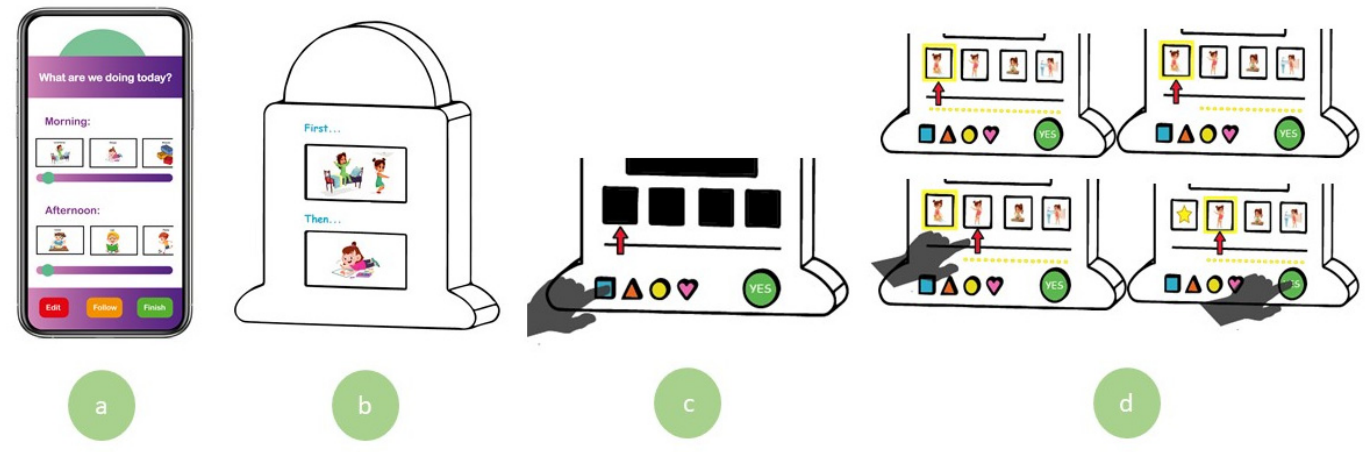

Figure 8. Human-interface interaction: main stages of the robot. (a) Creating a routine; (b) First-Then activities; (c) activity code; (d) activity and subtask.

Figure 8 shows a simplified drawing of the user-interface interaction for these stages. 
Pepe has an interactive interface (see interactive elements in Table 4) to control the different stages and interact through the different activities.

Table 4. Interactive elements of the interface.

\begin{tabular}{|c|c|c|}
\hline $\begin{array}{l}\text { Interaction Design } \\
\text { Elements }\end{array}$ & & Function \\
\hline \multirow{3}{*}{ Screens } & \multicolumn{2}{|c|}{ Shows First-Then activities } \\
\hline & \multicolumn{2}{|c|}{ Shows images of activities; show the subdivision of tasks } \\
\hline & \multicolumn{2}{|c|}{ Shows the reward system to the child } \\
\hline Red arrow & \multicolumn{2}{|c|}{$\begin{array}{l}\text { Allows the child to point to a screen to mark the activity that is } \\
\text { being carried out }\end{array}$} \\
\hline YES button & \multicolumn{2}{|c|}{ Allows the child to confirm a response or action; affirmation } \\
\hline SHAPE buttons & \multicolumn{2}{|c|}{ Allows the child to enter the code (Key Code) } \\
\hline \multirow{4}{*}{ LED lights } & \multicolumn{2}{|c|}{ Time count: indicates the time remaining for each activity } \\
\hline & \multicolumn{2}{|c|}{ Enhances what is being done at the moment } \\
\hline & \multicolumn{2}{|c|}{ Positive reinforcement } \\
\hline & \multicolumn{2}{|c|}{ Facial expressions, identity } \\
\hline \multirow{6}{*}{ Speaker } & \multirow{4}{*}{ Child's voice } & Guides through the time of use \\
\hline & & Positive reinforcement \\
\hline & & Time count \\
\hline & & Identity \\
\hline & \multirow{2}{*}{ Music } & Indicates if the answer is correct \\
\hline & & Positive reinforcement \\
\hline
\end{tabular}

Lastly, Table 5 details the user-product interaction, relating the functions and subfunctions (FR, NFR, and SR) and the corresponding actions of the user.

Table 5. List of product functions and user actions.

\begin{tabular}{|c|c|c|c|}
\hline \multicolumn{3}{|c|}{ Product Functions } & \multirow{2}{*}{$\begin{array}{l}\text { User Actions } \\
\text { P: Parent/Supervisor } \\
\text { C: Child with ASD }\end{array}$} \\
\hline Functions & & Subfunctions/Functional Requirements & \\
\hline \multirow{6}{*}{$\begin{array}{l}\text { Stage } 1 . \\
\text { Establishment } \\
\text { and approval } \\
\text { of the routine }\end{array}$} & \multirow[b]{3}{*}{$\begin{array}{l}\text { Routine proposal } \\
\text { to parents }\end{array}$} & The application is activated & Activate the application $(\mathrm{P})$ \\
\hline & & FR 1 & Find desired command $(\mathrm{P})$ \\
\hline & & $\begin{array}{l}\text { Presents routine proposal (application) } \\
\text { FR } 8, \mathbf{9}, \mathbf{1 1}, \mathbf{1 2}\end{array}$ & $\begin{array}{l}\text { Request routine for } X \text { time }(\mathrm{P}) \\
\text { Check routine }(\mathrm{P}) \\
\text { Decide whether to modify or approve }(\mathrm{P})\end{array}$ \\
\hline & \multirow{3}{*}{$\begin{array}{l}\text { Modification/ } \\
\text { routine approval }\end{array}$} & $\begin{array}{l}\text { The routine is modified (app) } \\
\text { FR } 5, \mathbf{9}\end{array}$ & If the parent modifies the routine \\
\hline & & $\begin{array}{l}\text { The routine is approved (app) } \\
\text { FR } 5, \mathbf{9}\end{array}$ & \multirow{2}{*}{ If the parent approves of the routine } \\
\hline & & $\begin{array}{l}\text { The routine is recorded and sent to the robot } \\
\text { FR } \mathbf{6}, \mathbf{8}, \mathbf{1 2}\end{array}$ & \\
\hline \multirow{3}{*}{ Turn robot $\mathrm{ON}$} & & $\begin{array}{l}\text { Robot ON } \\
\text { FR } 4\end{array}$ & Press the ON/OFF button (C) \\
\hline & & $\begin{array}{l}\text { Verbal welcome message } \\
\text { FR } 2,3, \mathbf{6}\end{array}$ & \multirow{2}{*}{ Check that the toy is on $(\mathrm{C})$} \\
\hline & & $\begin{array}{l}\text { The expression "SMILE" lights up } \\
\text { FR } 2, \mathbf{3}, \mathbf{4}, \mathbf{6}\end{array}$ & \\
\hline
\end{tabular}


Table 5. Cont.

\begin{tabular}{|c|c|c|}
\hline \multicolumn{2}{|l|}{ Product Functions } & \multirow{2}{*}{$\begin{array}{l}\text { User Actions } \\
\text { P: Parent/Supervisor } \\
\text { C: Child with ASD }\end{array}$} \\
\hline Functions & Subfunctions/Functional Requirements & \\
\hline \multirow{5}{*}{$\begin{array}{l}\text { Stage 2. Presentation of First-Then } \\
\text { activities }\end{array}$} & $\begin{array}{l}\text { Verbal message: start routine } \\
\text { FR } \mathbf{2}, \mathbf{4}, \mathbf{6}, \mathbf{1 0}\end{array}$ & Receive info: start the routine $(\mathrm{C})$ \\
\hline & $\begin{array}{l}\text { Ask the child verbally to turn it around } \\
\text { FR } 2,3,6,10\end{array}$ & $\begin{array}{l}\text { Turn robot around }(\mathrm{C}) \\
\text { Check position }(\mathrm{C})\end{array}$ \\
\hline & $\begin{array}{l}\text { Shows activities First-Then } \\
\text { FR } \mathbf{2} \mathbf{4} \mathbf{1 0}, \mathbf{1 1}, \mathbf{1 3}\end{array}$ & Receive info: tasks to perform $(\mathrm{C})$ \\
\hline & $\begin{array}{l}\text { Verbal message: identify the first activity and } \\
\text { enter the code }\end{array}$ & Identify the first activity $(\mathrm{C})$ \\
\hline & FR $3,6,10,14$ & Ask the supervisor for KeyCode (C) \\
\hline \multirow{8}{*}{$\begin{array}{l}\text { Stage } 3 \text {. } \\
\text { Identification and introduction of } \\
\text { the activity code }\end{array}$} & The code is displayed in the app & Identify the activity $(\mathrm{P})$ \\
\hline & FR $3,10,15$ & Communicate the code to the child $(\mathrm{P})$ \\
\hline & $\begin{array}{l}\text { Allows code input } \\
\text { FR } 2,3,7,15\end{array}$ & $\begin{array}{l}\text { Receive supervisor info: code }(\mathrm{C}) \\
\text { Enter the code }(\mathrm{C}) \\
\text { Check code }(\mathrm{C})\end{array}$ \\
\hline & $\begin{array}{l}\text { Acquire emotion "HAPPY" } \\
\text { FR 2, 4, 6, 16 }\end{array}$ & \multirow{3}{*}{ If the code is correct } \\
\hline & 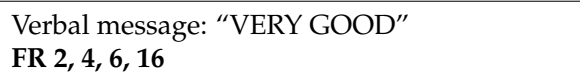 & \\
\hline & $\begin{array}{l}\text { Plays "SUCCESS" melody } \\
\text { FR } \mathbf{2 , 4} \mathbf{4} \mathbf{6} \mathbf{1 6}\end{array}$ & \\
\hline & $\begin{array}{l}\text { Acquire "SAD" emotion } \\
\text { FR 4, 6, 17 }\end{array}$ & \multirow{2}{*}{ If the code is incorrect } \\
\hline & $\begin{array}{l}\text { Plays "FAILURE" melody } \\
\text { FR 4, 6, } 17\end{array}$ & \\
\hline \multirow{13}{*}{ Stage 4. Activity and subtasks } & $\begin{array}{l}\text { Warns that the activity will begin } \\
\text { FR } 2, \mathbf{4}, \mathbf{6}, \mathbf{1 0}\end{array}$ & Verify that the activity is going to start $(\mathrm{C})$ \\
\hline & $\begin{array}{l}\text { Displays tasks and subtasks } \\
\text { FR } \mathbf{2 , 4}, \mathbf{1 0}, \mathbf{1 1} \mathbf{1 3}\end{array}$ & Receive info: task and subtasks to perform $(\mathrm{C})$ \\
\hline & $\begin{array}{l}\text { The light for the first subtask comes on } \\
\text { FR } \mathbf{2}, \mathbf{4}, \mathbf{1 0}, \mathbf{1 1}\end{array}$ & Identify the first subtask to perform $(C)$ \\
\hline & Timeline lights up & Receive info/check: start first subtask (C) \\
\hline & FR $2,3,4,10,13,14$ & Start with the first subtask (C) \\
\hline & $\begin{array}{l}\text { Time lights turn off progressively } \\
\text { FR } \mathbf{2}, \mathbf{3}, \mathbf{4}, \mathbf{1 0}, \mathbf{1 3}, \mathbf{1 4}\end{array}$ & Receive/check info: time is passing $(C)$ \\
\hline & $\begin{array}{l}\text { Verbal message: time to switch subtasks } \\
\text { FR } \mathbf{2}, \mathbf{3} \mathbf{4}, \mathbf{1 0}, \mathbf{1 3}, \mathbf{1 4}\end{array}$ & $\begin{array}{l}\text { Receive info: switch subtasks (C) } \\
\text { Move the arrow to the next subtask (C) } \\
\text { Check arrow position (C) }\end{array}$ \\
\hline & $\begin{array}{l}\text { The next activity light turns on } \\
\text { FR } 2,3,4,7,10\end{array}$ & \multirow{4}{*}{ Press the YES button $(\mathrm{C})$} \\
\hline & $\begin{array}{l}\text { Verbal message: “VERY GOOD” } \\
\text { FR } \mathbf{2}, \mathbf{3}, \mathbf{4}, \mathbf{6}, \mathbf{1 6}\end{array}$ & \\
\hline & $\begin{array}{l}\text { Plays "SUCCESS" melody } \\
\text { FR } \mathbf{2 , 4 , 6 , 1 6}\end{array}$ & \\
\hline & $\begin{array}{l}\text { Remember how long the subtask took } \\
\text { FR } \mathbf{6 , 8 , 1 2}\end{array}$ & \\
\hline & $\begin{array}{l}\text { A star appears in the completed subtask } \\
\text { FR } \mathbf{2 , 4 , 6 , 1 6 , 1 7}\end{array}$ & Verify: the activity is complete $(\mathrm{C})$ \\
\hline & $\begin{array}{l}\text { The star is saved in the app } \\
\text { FR } \mathbf{1 6}, \mathbf{1 7}\end{array}$ & Receive info: number of stars achieved $(\mathrm{P}, \mathrm{C})$ \\
\hline
\end{tabular}


Table 5. Cont.

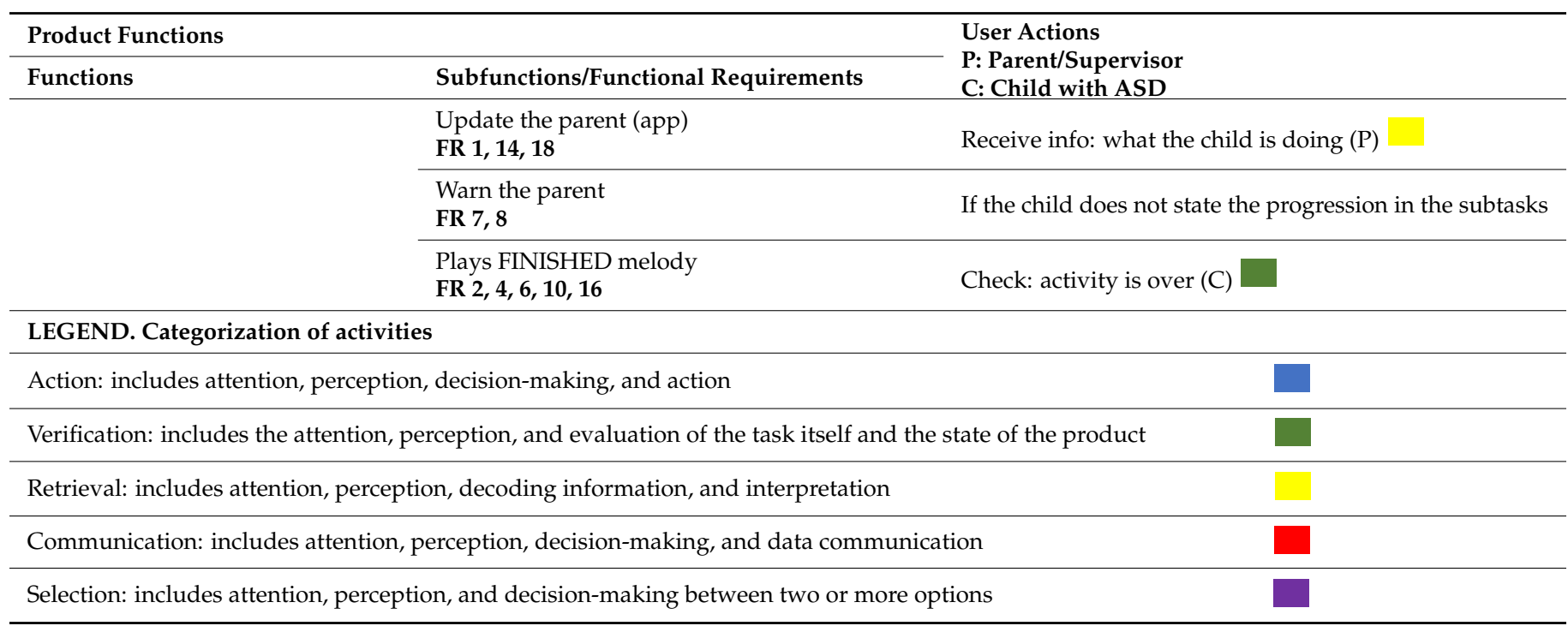

\subsection{Phases 6 and 7: Prototyping and Testing}

Once the detail design was established, the prototyping phase allowed the final proposal to be validated. As indicated by the ASDesign methodology, the prototype aims to validate the following aspects: (1) aesthetic (look and feel), (2) structural, (3) functional, (4) technical, and (5) integrated. For this work, technical, functional, and integration prototypes (where the look and feel aspects were also included) were developed.

The technical prototype was manufactured using an Arduino and the Arduino software. It included buttons, photoresistors, and a clock module as sensors, and LED lights, a speaker, and a buzzer as actuators. This made it possible to test the following elements: (3) KeyCode State and (4) Activity State. All these functions, together with the corresponding lights and sounds, were tested. Thus, the electronic circuit was established to create the electronic skeleton of the robot (Figure 9, left). Subsequently, this skeleton was integrated into a working prototype to test the different user-product interactions. For this prototype, the "Wizard of Oz" prototyping method [57] was used for the screens, in order to get a complete perspective of the entire functionality (see Figure 9, right).

Finally, an integration prototype (see Figure 10) was manufactured, including elements of materiality and appearance (look and feel) combined with the electronic skeleton. This was developed with the following materials: foam boards, cardboard, cork, felt, foam, bubble wrap, PET spiral bracelets, aluminum foil, and cellophane paper. This last prototype was tested with a child with ASD, a typically developing child, and an adult.

For the test with the integration prototype (Figure 11), a list of assumptions to be validated was created: (1) structure and resistance, (2) visual elements, (3) sound elements, (4) motor action elements and (5) learning and understanding. From this test, it was concluded that the user was attracted to the robot, its shape, colors, and textures. The lights and sounds did not disturb him and the textures were attractive, especially the arms, as they quickly attracted attention. Facial expressions were also a key element in capturing the user's attention. The way to interact with the different elements of the interface (arrow and buttons) was understood. The images (in this case pictograms) were understandable. Choosing answers in the interface, as well as entering the "Key Code", was intuitive. Additionally, the sequence of moving the arrow and pressing the green button was clear to the user. The user was willing to play as long as they understood the flow of the interaction. This last aspect suggests that, for the early stages, an adult should be present and help the child. 

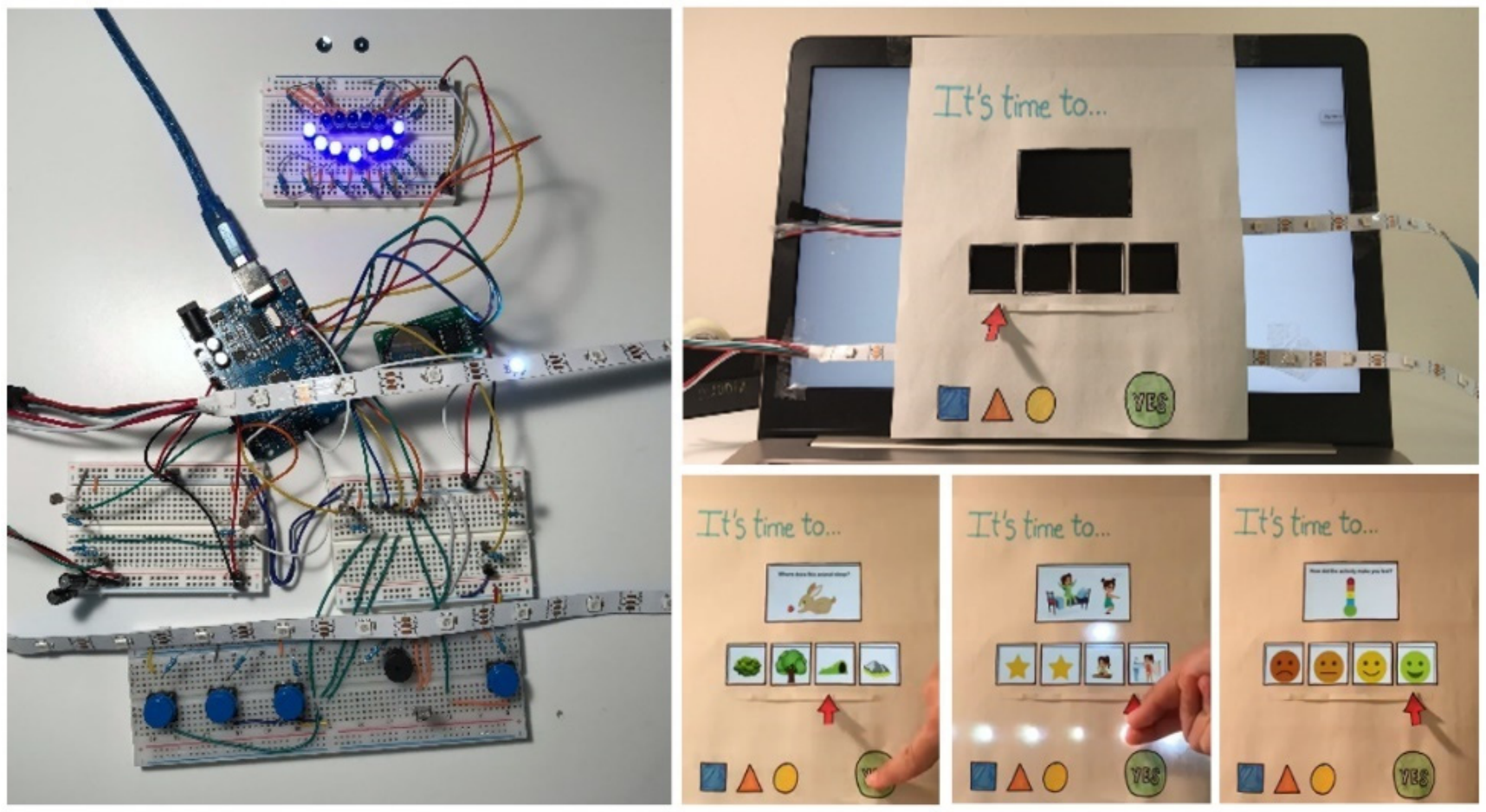

Figure 9. Technical (left) and functional (right) prototype.
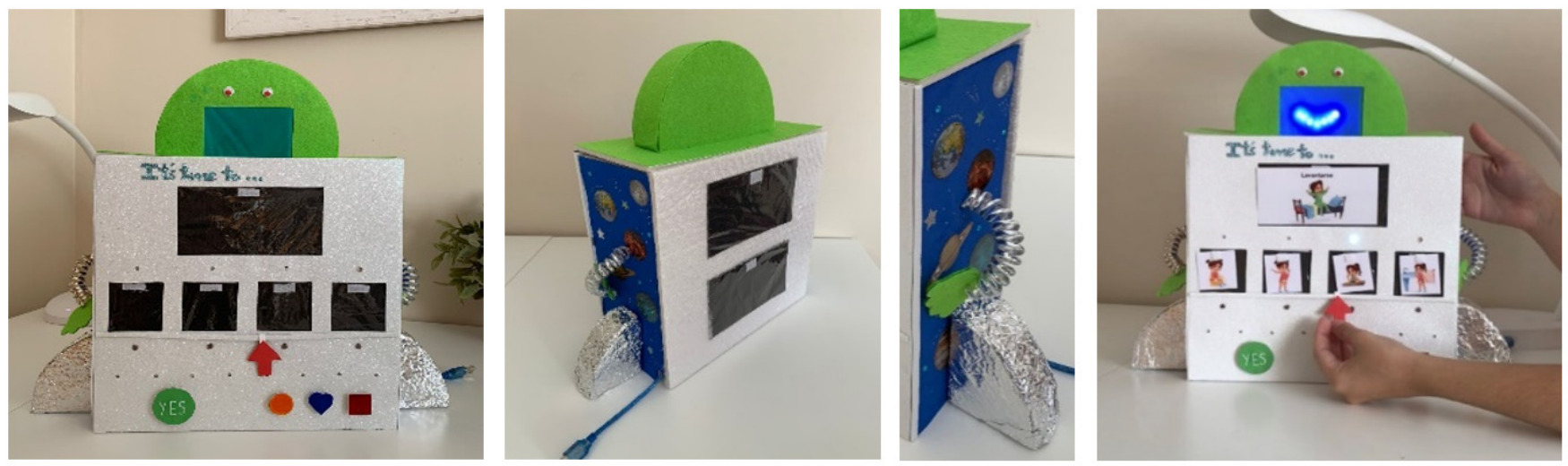

Figure 10. Integration prototype.
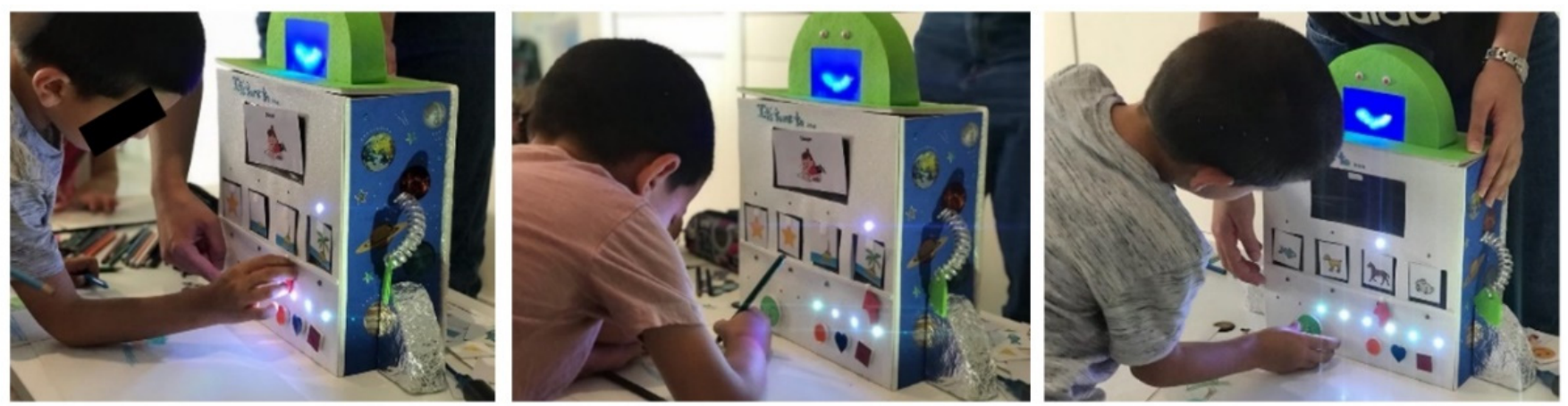

Figure 11. Testing the prototype with the user.

\subsection{Design Validation}

The characteristics of the Pepe robot make it an interactive and smart product. This section evaluates the design, making use of different principles and data from the scientific 
and technical literature. This evaluation, together with the verification of the design through prototyping and testing with the target user, establishes the suitability of the ASDesign method.

Through its different functions and elements, Pepe integrates the following perspectives of interactivity: (1) Dialogue interaction (interaction is perceived by children as a dialogue, where the different elements are used to provide information and wait for a response; in this case, the dialogue includes three actors: parents, children, and Pepe [58]); (2) System interaction (the process of learning and interpretation of information by the robot, to subsequently shape and establish how the dialogue will evolve) [58]; (3) Transmission interaction (present information to the child for him to learn and interpret) [59]; and (4) Agent-based interaction (based on the instructions given by the user to perform a specific task that determines how the user-product interaction will develop) [60]. The combination of these perspectives makes the interaction adaptive to the child's development, resulting in an evolution of dialogue, thus being interconnected perspectives.

The fact that it is also smart was demonstrated by Cagiltay et al. (2014), who argued that "smart toys are new forms of toys that incorporate tangible objects and electronic chips to provide two-way interactions that lead to purposeful tasks with behavioral or cognitive merit" [41].

According to Rijsdijk and Hultink, the seven dimensions of the smartness of a product are autonomy, adaptability, reactivity, multifunctionality, the ability to cooperate, human interaction, and personality [61]. Thus, the degree of smartness of a product is measured to the extent that it has one or more of the following characteristics. Table 6 explores these dimensions. This check validates the ASD_T2 and ASD_T3 modules.

Table 6. Smart dimensions of a product.

\begin{tabular}{|c|c|c|}
\hline Dimension & Definition & Implementation with ASD_T2 and ASD_T3 \\
\hline Autonomy & $\begin{array}{l}\text { The extent to which a product is able to } \\
\text { operate independently and meet } \\
\text { objectives without user interference. }\end{array}$ & $\begin{array}{l}\text { Although the collaboration of parents is required to insert preferences, } \\
\text { Pepe guides the child throughout the day independently and without } \\
\text { the need for supervision. }\end{array}$ \\
\hline Adaptability & $\begin{array}{l}\text { The ability of a product to improve the } \\
\text { match between its functioning and its } \\
\text { environment [62]. }\end{array}$ & $\begin{array}{l}\text { Pepe is able to save and interpret information about the child's } \\
\text { performance (time required by a task, how it makes him or her feel, } \\
\text { which visual and auditory supports work best, etc.), continuously } \\
\text { adapting its interactions to the needs of the child. }\end{array}$ \\
\hline Reactivity & $\begin{array}{l}\text { The ability of a product to react to } \\
\text { changes in its environment [63]. }\end{array}$ & $\begin{array}{l}\text { Pepe is able to react to the child's actions through the different } \\
\text { sensors-buttons, light sensors, sound sensors, or time modules-and } \\
\text { adapt its behavior. }\end{array}$ \\
\hline Multifunctionality & $\begin{array}{l}\text { A single product fulfills multiple } \\
\text { functions [64]. }\end{array}$ & $\begin{array}{l}\text { Although it fulfills the main function of guiding the child through a } \\
\text { routine, Pepe includes different modalities and subfunctions to meet } \\
\text { this objective: establishment of a routine, the introduction of codes, } \\
\text { monitoring of activities, monitoring of the child's achievements, and } \\
\text { help system. }\end{array}$ \\
\hline Ability to cooperate & $\begin{array}{l}\text { Ability to cooperate with other devices } \\
\text { to achieve a common goal. }\end{array}$ & $\begin{array}{l}\text { In the case of this robot, it can be connected to the mobile application } \\
\text { so that parents can insert their preferences, modify the routine, and be } \\
\text { aware of what their children are doing. }\end{array}$ \\
\hline Human interaction & $\begin{array}{l}\text { The degree to which the product } \\
\text { communicates and interacts with the } \\
\text { user in a natural and humane way. }\end{array}$ & $\begin{array}{l}\text { The Pepe robot communicates with the user visually and verbally, in } \\
\text { an intuitive way, using familiar expressions, facial expressions, and } \\
\text { positive reinforcements that motivate the child. }\end{array}$ \\
\hline Personality & $\begin{array}{l}\text { The ability of the product to show the } \\
\text { properties of a believable character [63]. }\end{array}$ & $\begin{array}{l}\text { The Pepe robot has a believable personality thanks to its material } \\
\text { elements that give it a humanoid appearance (eyes, mouth, arms), as } \\
\text { well as a child voice that gives it the personality of a playmate. }\end{array}$ \\
\hline
\end{tabular}

Table 7 compiles the set of results obtained from the testing according to the user experience analysis parameters as established by Donald Norman [65-67]. 
Table 7. Testing results: user experience analysis.

\begin{tabular}{cc}
\hline Basis & Usability Analysis \\
\hline Visibility & $\begin{array}{r}\text { All interface elements are visible. Having two different sides with screens creates two separate } \\
\text { interfaces, avoiding distractions in the different stages. The design is safe. }\end{array}$ \\
\hline Feedback & $\begin{array}{r}\text { It is achieved with visual, perceptual, and proprioceptive stimuli. Every action of the product has } \\
\text { immediate feedback, which keeps the child engaged. The lights and sounds do not disturb the child. }\end{array}$ \\
\hline Affordance & $\begin{array}{r}\text { All the affordances have an intuitive meaning that is easy for the user to understand. The green } \\
\text { button and red arrow are very familiar. }\end{array}$ \\
Mapping & $\begin{array}{r}\text { Having the screens in a horizontal disposition is intuitive for the child. The action-reaction } \\
\text { consistency of musical sounds and lights is adequate. The "light count down" was not completely } \\
\text { understood but could be due to the need of having a learning period. }\end{array}$ \\
Constraints & $\begin{array}{r}\text { Correct. They reduce the probability of human error. The different simultaneous stimuli of the } \\
\text { interface help to focus attention on the tasks and the product; the mechanical restrictions and design } \\
\text { of buttons and arrow avoid unwanted actions and help to reduce errors by restricting the type of } \\
\text { interactions that the user can carry out. }\end{array}$ \\
\hline Consistency & $\begin{array}{r}\text { Aesthetic, functional, internal, and external consistency is correct. The grip, movement, and } \\
\text { stereotype patterns are correct. }\end{array}$ \\
\hline Reinforcements & $\begin{array}{r}\text { Correct. Through visual (light and color), auditory (musical sounds), and proprioceptive (textures, } \\
\text { movements, grip, pulsation, pressure, and force generation) stimulation. }\end{array}$ \\
\hline
\end{tabular}

Table 8 compiles the set of results obtained from the testing regarding effectivity, efficiency, and satisfaction [68]. The results have been divided into two phases: (1) the learning period, which involved following simple instructions, and (2) following the activity, which involved understanding the complete flow of the interaction.

Table 8. Testing results: effectivity, efficiency, and satisfaction.

\begin{tabular}{|c|c|c|}
\hline \multirow{2}{*}{ Effectivity } & Phase 1 & $\begin{array}{l}\text { Completed of activities: The child was able to complete simple instructions: move the arrow, press a sequence of } \\
\text { buttons, turn the robot around. } \\
\text { Failures: The child did not make many mistakes regarding simple instructions. } \\
\text { Number of times that the child stopped the activity: When the child understood the instructions, there were no } \\
\text { interruptions. } \\
\text { Number of times that the child lost control over an activity: The child lost control because of a loss of attention, but } \\
\text { not due to misunderstanding. }\end{array}$ \\
\hline & Phase 2 & $\begin{array}{l}\text { Completed of activities: The child struggled to understand the flow of the interaction in such a short period. Only } \\
\text { simple activities could be performed. } \\
\text { Failures: The child was not able to follow the complete flow of an activity, reinforcing the need of a learning period. } \\
\text { Number of times that the child stopped the activity: The activities had to be stopped several times because of a loss } \\
\text { of attention. This could be because the prototype did not integrate real screens. } \\
\text { Number of times that the child lost control over an activity: The child lost control because of a loss of attention and } \\
\text { misunderstanding. }\end{array}$ \\
\hline \multirow[t]{2}{*}{ Efficiency } & Phase 1 & $\begin{array}{l}\text { Time to complete the task: The simple instructions were completed immediately, which proves that the child } \\
\text { understood the functionality of the different elements. } \\
\text { Time loss due to errors: When the child understood the tasks, the tasks were completed quickly. } \\
\text { The number of elements used from the interface: All elements on the interface were used. } \\
\text { Time spent to learn: The simple instructions were easily understood and performed. The child was already familiar } \\
\text { with the elements and sequence of use. }\end{array}$ \\
\hline & Phase 2 & $\begin{array}{l}\text { Time to complete the task: The child was not able to complete the flow of an activity. } \\
\text { Time loss due to errors: The loss of attention led to time loss. } \\
\text { The number of elements used from the interface: All elements on the interface were used. } \\
\text { Time spent to learn: Half an hour was not enough for the child to learn the flow of an activity. }\end{array}$ \\
\hline \multirow[b]{2}{*}{ Satisfaction } & Phase 1 & $\begin{array}{l}\text { Positive reactions: The user enjoyed the sensory stimulation from the product: lights, music, tactile stimuli. He or she } \\
\text { was attracted to the product. } \\
\text { Times that the user encountered problems: The user did not encounter problems with simple instructions. }\end{array}$ \\
\hline & Phase 2 & $\begin{array}{l}\text { Positive reactions: The user enjoyed the sensory stimulation from the product: lights, music, tactile stimuli. He or she } \\
\text { was attracted to the product. } \\
\text { Times that the user encountered problems: The user encountered problems understanding the whole activity, which } \\
\text { led to a loss of attention. }\end{array}$ \\
\hline
\end{tabular}




\section{Results and Discussion}

ASDesign and the presented case study (the Pepe robot) fit the development of a user-centered methodology for assistive technology design in a domestic context that helps children with ASD plan and self-manage a daily routine. This methodology is based on the principles of Positive Behavioral Support; that is, it is committed to products that allow a long-term development and negotiation process in which the child with ASD learns to self-regulate progressively, with the ultimate goal of independence.

In addition to this, the scope of the ASDesign method allows one to create products that can be used in periods of confinement. Although the line of work arises from the situation derived from the pandemic, the method extends the context of use to the new normal in which the reconciliation of the working day with the care of the child with ASD can be a challenge for many families. Thus, ASDesign is a methodology aimed at the design of assistive technology for children with ASD, which gradually helps them to become more independent in the follow-up of a routine, with the intention of improving their self-autonomy in situations in which they need support that cannot be granted given the social context in which they find themselves. Including desirable periods within the term "confinement" is of great interest. Several studies show that the experience of confinement caused by the health crisis has led to social and structural changes in the labor market that could be definitively implemented in daily life, such as telework, online training, or intensive or reduced working days, to which professionals and families must adapt [3-5]. In addition, the new trends in automation and industrialization 4.0 will generate positions with more responsibility, geographical distribution, and flexibility, which also means an alteration of the working schedule.

The ASDesign method allows one to integrate into mid- and high-tech products the properties of multifunctionality, smartness, and interactivity, complying with the following principles:

(1) Adaptability: Design of products that adapt to the needs, desires, and abilities of the child by collecting information from his performance with the product and interacting with parents. This adaptability allows assistive products to interact with the child and adapt to different needs; that is, technology changes its behavior as the child progresses.

(2) Agent Design: It is important that products have the interaction design based on agencies [56] as an essential element. This will allow for a negotiation of responsibilities, giving control to the parents during the early stages and allowing the child to make decisions progressively. Products must be adapted to the needs and preferences of children, gradually giving them autonomy and therefore the independence they need for their social and personal development.

(3) Sensoriality: Assistive technology should be designed based on the accentuated needs and special sensory characteristics that children with ASD have. ASDesign relies on extensive user analysis to design products that present and collect information in an intuitive and engaging way for these children. In this way, it proposes to move away from the limitations of 2D technologies and combine traditional (low) and computational (mid-high tech) elements and materials to ensure the safety, comfort, and correct physical, cognitive (perceptual, sensory, and emotional) adaptation of children with ASD.

(4) Learning through play: ASDesign focuses on the planning and structuring of routines in a domestic context. Therefore, making use of the advantages offered by medium/high assistive technology, this methodology proposes a playful approach, in which routine gamification is put into practice by having a reward system to keep the child motivated.

With these four principles, ASDesign can be applied to high-tech products that aim to help children with ASD be more independent in their daily routine. It has all the design stages, the task planning is correct, and the modules ASDT_T1, 2 and 3 have been validated. 
Lastly, as future lines of work, it would be interesting to expand the scope of the ASDesign methodology to the spectrum levels (2 and 3), enabling the design of interactive and smart products for other difficulties and needs of autism. Another future development would involve the creation of a module for the evaluation of design solutions, which would provide the design team with quantitative indicators of the adequacy of the potential design. Finally, the development of a computer application that facilitates the use of the ASDesign methodology is proposed, linked to a database that makes the update of the ASD_T2 and T3 tools more flexible.

\section{Conclusions}

Although some parents have seen "positive" effects of confinement, for example, seeing their children be more relaxed by not feeling the pressure that exists in education centers for having to socialize with others or perform certain tasks, most studies show that negative effects have prevailed [11,15]. Children with ASD have experienced a loss of independence and communication skills [12]. Social isolation, lack of services due to the economic downturn, and job loss further accentuate the inequality of opportunity gap for children with ASD and their families [11,19]. On the other hand, many of the new daily and work practices derived from confinement (such as telework or the globalization of the labor market) could be implemented indefinitely, which will require new tools to address family reconciliation.

This work develops the ASDesign method, a user-centered method for the design of assistive technology and smart products that helps children with ASD follow a routine and manage tasks autonomously. The method has the scope of user-centered technology design; that is, it can be used and configured comfortably and safely by children (and supervised by parents), thus helping them to plan a routine and be more independent in their day-to-day. This methodology has been applied to the Pepe Robot case study, which has obtained very good results when tested with the target user, thus validating the proposed method.

This work aims to improve the living conditions, health, and social welfare of groups that have been negatively affected by the pandemic. This research contributes to engineering and design fields, and more specifically to the development of science that serves society, with the end goal of improving well-being and social sustainability.

Author Contributions: Conceptualization, R.C. and M.E.P.; formal analysis, R.C.; investigation, R.C. and M.E.P.; methodology, R.C. and M.E.P.; software, R.C.; design and prototyping: R.C.; supervision, M.E.P.; validation, R.C. and M.E.P.; writing-original draft, R.C. and M.E.P.; writing-review and editing, R.C. and M.E.P. All authors have read and agreed to the published version of the manuscript.

Funding: This research received no external funding.

Institutional Review Board Statement: Not applicable.

Informed Consent Statement: Informed consent was obtained from all subjects involved in the study. Written informed consent has been obtained from the patient(s) to publish this paper.

Data Availability Statement: The data presented in this study (Annex I and II) are available upon request from the corresponding author.

Acknowledgments: We thank TuYTEA, Asociación TAJIBO, Asociación Autismo Sevilla, Centro Psicopedagógico Impulso, el Gabinete LegoDUO, Asociación Seta, Neurointegra, and AOSA-TEA for their interest, commitment, and collaboration in the project.

Conflicts of Interest: The authors declare no conflict of interest.

\section{References}

1. Colizzi, M.; Sironi, E.; Antonini, F.; Ciceri, M.L.; Bovo, C.; Zoccante, L. Psychosocial and Behavioral Impact of COVID-19 in Autism Spectrum Disorder: An Online Parent Survey. Brain Sci. 2020, 10, 341. [CrossRef]

2. Smile, S.C. Supporting children with autism spectrum disorder in the face of the COVID-19 pandemic. CMAJ 2020, 192, E587. [CrossRef] 
3. Baert, S.; Lippens, L.; Moens, E.; Sterkens, P.; Weytjens, J. How Do We Think the COVID-19 Crisis Will Affect Our Careers (If Any Remain); Global Labor Organization: Essen, Germany, 2020.

4. $\quad$ Baert, S.; Lippens, L.; Moens, E.; Sterkens, P.; Weytjens, J. The COVID-19 Crisis and Telework: A Research Survey on Experiences, Expectations and Hopes; Global Labor Organization: Essen, Germany, 2020.

5. $\quad$ Brynjolfsson, E.; Horton, J.J.; Ozimek, A.; Rock, D.; Sharma, G.; Tuye, H.-Y.; Upwork, A.O. COVID-19 and Remote Work: An Early Look at US Data; National Bureau of Economic Research: Cambridge, MA, USA, 2020.

6. Chia, G.L.C.; Anderson, A.; McLean, L.A. Use of Technology to Support Self-Management in Individuals with Autism: Systematic Review. Rev. J. Autism Dev. Disord. 2018, 5, 142-155. [CrossRef]

7. Iwarsson, S.; Ståhl, A. Accessibility, Usability and Universal Design-Positioning and Definition of Concepts Describing PersonEnvironment Relationships. Disabil. Rehabil. 2003, 25, 57-66. [CrossRef]

8. Merriam-Webster Confined I Definition of Confined. Available online: https:/ / www.merriam-webster.com/dictionary/confined (accessed on 21 October 2021).

9. American Psychiatric Association. Diagnostic and Statistical Manual of Mental Disorders: DSM-5; American Psychiatric Association: Washington, DC, USA, 2013; ISBN 0890425558.

10. Resource Guide I Autism Speaks. Available online: https:/ / www.autismspeaks.org/resource-guide (accessed on 5 March 2020)

11. Spain, D.; Mason, D.; Capp, J.S.; Stoppelbein, L.; White, W.S.; Happé, F. "This May Be a Really Good Opportunity to Make the World a More Autism Friendly Place": Professionals' Perspectives on the Effects of COVID-19 on Autistic Individuals. Res. Autism Spectr. Disord. 2021, 83, 101747. [CrossRef]

12. Tokatly Latzer, I.; Leitner, Y.; Karnieli-Miller, O. Core Experiences of Parents of Children with Autism during the COVID-19 Pandemic Lockdown. Autism 2021, 25, 1047-1059. [CrossRef]

13. Yılmaz, B.; Azak, M.; Şahin, N. Mental Health of Parents of Children with Autism Spectrum Disorder during COVID-19 Pandemic: A Systematic Review. World J. Psychiatry 2021, 11, 388-402. [CrossRef] [PubMed]

14. Baweja, R.; Brown, S.L.; Edwards, E.M.; Murray, M.J. COVID-19 Pandemic and Impact on Patients with Autism Spectrum Disorder. J. Autism Dev. Disord. 2021, 10, 1-10. [CrossRef] [PubMed]

15. Mumbardó-Adam, C.; Barnet-López, S.; Balboni, G. How Have Youth with Autism Spectrum Disorder Managed Quarantine Derived from COVID-19 Pandemic? An Approach to Families Perspectives. Res. Dev. Disabil. 2021, 110, 103860. [CrossRef]

16. Fergusson, E.F.; Jimenez-Muñoz, M.; Feerst, H.; Vernon, T.W. Predictors of Satisfaction with Autism Treatment Services during COVID-19. J. Autism. Dev. Disord. 2021, 1-12. [CrossRef]

17. Degli Espinosa, F.; Metko, A.; Raimondi, M.; Impenna, M.; Scognamiglio, E. A Model of Support for Families of Children with Autism Living in the COVID-19 Lockdown: Lessons from Italy. Behav. Anal. Pract. 2020, 13, 550-558. [CrossRef]

18. Alhuzimi, T. Stress and Emotional Wellbeing of Parents Due to Change in Routine for Children with Autism Spectrum Disorder (ASD) at Home during COVID-19 Pandemic in Saudi Arabia. Res. Dev. Disabil. 2021, 108, 103822. [CrossRef]

19. Manning, J.; Billian, J.; Matson, J.; Allen, C.; Soares, N. Perceptions of Families of Individuals with Autism Spectrum Disorder during the COVID-19 Crisis. J. Autism Dev. Disord. 2020, 51, 2920-2928. [CrossRef]

20. Narzisi, A. Autism Spectrum Condition and COVID-19: Issues and Chances. Humanist. Psychol. 2020, 48, 378-381. [CrossRef]

21. WHO. International Classification of Functioning, Disability and Health; World Health Organization: Geneva, Switzerland, 2014.

22. Lentini, R.; Vaughn, B.J.; Fox, L. University of South Florida Teaching Tools for Young Children with Challenging Behavior. In Early Intervention Positive Behavior Support; University of South Florida: Tampa, FL, USA, 2005.

23. Hopkins, J. Assistive Technology: 10 things to know. Libr. Media Connect. 2006, 25, 12-14.

24. Establish Morning or Evening Routine / Happy Kids Timer Chores during COVID-19. Available online: https://happykidstimer. $\mathrm{com} /$ (accessed on 2 April 2021).

25. Choiceworks App. Available online: http://www.beevisual.com/ (accessed on 2 April 2021).

26. Syriopoulou-Delli, C.K.; Gkiolnta, E. Review of Assistive Technology in the Training of Children with Autism Spectrum Disorders. Int. J. Dev. Disabil. 2020. [CrossRef]

27. Castillo, J.; Goulart, C.; Valadão, C.; Caldeira, E.; Bastos, T. Robótica Móvil: Una Herramienta Para Interacción de Niños Con Autismo. In Proceedings of the VII Congreso Iberoamericano de Tecnologías de Apoyo a la Discapacidad-IBERDISCAP, Santiago de Los Caballeros, Dominican Republic, 28-29 November 2013.

28. Bekele, E.; Crittendon, J.A.; Swanson, A.; Sarkar, N.; Warren, Z.E. Pilot Clinical Application of an Adaptive Robotic System for Young Children with Autism. Autism 2014, 18, 598-608. [CrossRef] [PubMed]

29. Robins, B.; Dautenhahn, K.; Te Boekhorst, R.; Billard, A. Robotic Assistants in Therapy and Education of Children with Autism: Can a Small Humanoid Robot Help Encourage Social Interaction Skills? Univers. Access Inf. Soc. 2005, 4, 105-120. [CrossRef]

30. Shamsuddin, S.; Yussof, H.; Mohamed, S.; Hanapiah, F.A. Design and Ethical Concerns in Robotic Adjunct Therapy Protocols for Children with Autism. Procedia Comput. Sci. 2014, 42, 9-16. [CrossRef]

31. Leka. Available online: https:/ / leka.io/en/product.html (accessed on 30 March 2021).

32. University of Hertfordshire. Kaspar the Social Robot. Available online: https://www.herts.ac.uk/kaspar/the-social-robot (accessed on 30 March 2021) 
33. Attawibulkul, S.; Asawalertsak, N.; Suwawong, P.; Wattanapongsakul, P.; Jutharee, W.; Kaewkamnerdpong, B. Using a Daily Routine Game on the BLISS Robot for Supporting Personal-Social Development in Children with Autism and Other Special Needs. In Proceedings of the 58th Annual Conference of the Society of Instrument and Control Engineers of Japan, SICE 2019, Hiroshima, Japan, 10-13 September 2019; pp. 695-700. [CrossRef]

34. Meadan, H.; Ostrosky, M.M.; Triplett, B.; Michna, A.; Fettig, A. Using Visual Supports with Young Children with Autism Spectrum Disorder. Teach. Except. Child. 2011, 43, 28-35. [CrossRef]

35. Lucyshyn, J.M.; Albin, R.W.; Homer, R.H.; Mann, J.C.; Mann, J.A.; Wadsworth, G. Family Implementation of Positive Behavior Support for a Child with Autism: Longitudinal, Single-Case, Experimental, and Descriptive Replication and Extension. J. Posit. Behav. Interv. 2007, 9, 131-150. [CrossRef]

36. Cibrian, F.L.; Mercado, J.; Escobedo, L.; Tentori, M. A Step towards Identifying the Sound Preferences of Children with Autism. In Proceedings of the 12th EAI International Conference on Pervasive Computing Technologies for Healthcare, New York, NY, USA, 21-24 May 2018; ACM International Conference Proceeding Series. pp. 158-167. [CrossRef]

37. Dickie, V.A.; Baranek, G.T.; Schultz, B.; Watson, L.R.; McComish, C.S. Parent Reports of Sensory Experiences of Preschool Children With and Without Autism: A Qualitative Study. Am. J. Occup. Ther. 2009, 63, 172-181. [CrossRef] [PubMed]

38. Garrido, F.J.; Benjamín García, B. La Contaminación Acústica En Nuestras Ciudades. Colección Estud. Soc. 2003, 12, 1-248.

39. Seeman, L.; Cooper, M. Techniques for the The Cognitive and Learning Disabilities Accessibility Task Force (COGA). Available online: https:/ /w3c.github.io/coga/techniques/ (accessed on 14 April 2021).

40. Seeman, L.; Cooper, M. Cognitive Accessibility User Research. Available online: https://www.w3.org/TR/coga-user-research/ \#autism (accessed on 14 April 2021).

41. Cagiltay, K.; Kara, N.; Cigdem, C. Smart Toy Based Learning: Handbook of Research on Educational Communications and Technology, 4th ed.; Springer: Berlin/Heidelberg, Germany, 2014; pp. 1-1005. [CrossRef]

42. Caro, K.; Tentori, M.; Martinez-Garcia, A.I.; Alvelais, M. Using the FroggyBobby Exergame to Support Eye-Body Coordination Development of Children with Severe Autism. Int. J. Hum. Comput. Stud. 2017, 105, 12-27. [CrossRef]

43. Chen, J.; Wang, G.; Zhang, K.; Wang, G.; Liu, L. A Pilot Study on Evaluating Children with Autism Spectrum Disorder Using Computer Games. Comput. Hum. Behav. 2019, 90, 204-214. [CrossRef]

44. Cibrian, F.L.; Peña, O.; Ortega, D.; Tentori, M. BendableSound: An Elastic Multisensory Surface Using Touch-Based Interactions to Assist Children with Severe Autism during Music Therapy. Int. J. Hum. Comput. Stud. 2017, 107, 22-37. [CrossRef]

45. Contreras, V.; Fernández, D.; Pons, C.; Contreras, V.; Fernández, A.; Fabiana Pons, C. Interfaces Gestuales Aplicadas Como Complemento Cognitivo y Social Para Niños Con TEA. Rev. Iberoam. Tecnol. Educ. Educ. Tecnol. 2016, 17, 58-66.

46. Kara, N.; Cagiltay, K. Smart Toys for Preschool Children: A Design and Development Research. Electron. Commer. Res. Appl. 2020, 39, 100909. [CrossRef]

47. Malinverni, L.; Mora-Guiard, J.; Padillo, V.; Valero, L.; Hervás, A.; Pares, N. An Inclusive Design Approach for Developing Video Games for Children with Autism Spectrum Disorder. Comput. Hum. Behav. 2017, 71, 535-549. [CrossRef]

48. Dattolo, A.; Luccio, F.L. A Review of Websites and Mobile Applications for People with Autism Spectrum Disorders: Towards Shared Guidelines. In Lecture Notes of the Institute for Computer Sciences, Proceedings of the Social-Informatics and Telecommunications Engineering; Springer: Berlin/Heidelberg, Germany, 2017; Volume 195, pp. 264-273.

49. Dautenhahn, K.; Bond, A.; Cañamero, L.; Edmonds, B. Socially Intelligent Agents. Creating Relationships with Computers and Robots; Kluwer Academic Publishers: Dordrecht, The Netherlands, 2002; ISBN 978-1-4020-7057-0.

50. Javed, H.; Burns, R.; Myoughoon, J.; Howards, A.M.; Hyuk Park, C. A Robotic Framework to Facilitate Sensory Experiences for Children with Autism Spectrum Disorder: A Preliminary Study. ACM Trans. Hum.-Robot Interact. 2019, 9, 26. [CrossRef]

51. Pavlov, N. User Interface for People with Autism Spectrum Disorders. J. Softw. Eng. Appl. 2014, 7, 128-134. [CrossRef]

52. Diaz, R.; Peralta, M. Commercial Products for Children with Special Needs. In Future Challenges for an Inclusive Sector; University of Seville: Seville, Spain, 2021.

53. Hernández, A.; Peralta, M.E. Market. Research for Special Needs Products; University of Seville: Seville, Spain, 2020.

54. Porayska-Pomsta, K.; Frauenberger, C.; Pain, H.; Rajendran, G.; Smith, T.; Menzies, R.; Foster, M.E.; Alcorn, A.; Wass, S.; Bernadini, S.; et al. Developing Technology for Autism: An Interdisciplinary Approach. Pers. Ubiquitous Comput. 2012, 16, 117-127. [CrossRef]

55. Sanders, E.B.N.; Stappers, P.J. Convivial Toolbox: Generative Research for the Front End of Design; Laurence King Publishing: London, UK, 2012.

56. Wiberg, M. Interaction, New Materials \& Computing-Beyond the Disappearing Computer, towards Material Interactions. Mater. Des. 2014, 90, 1200-1206. [CrossRef]

57. Buxton, B. Sketching User Experiences: Getting the Design Right and the Right Design; Elsevier: San Francisco, CA, USA, 2007; ISBN 978-0-12-374037-3.

58. Iversen, O.S.; Krogh, P.G.; Petersen, M.G. Proceedings of the Fourth Danish Human-Computer Interaction Research Symposium; Aalborg University: Aalborg, Denmark, 2003.

59. Hornbæk, K.; Oulasvirta, A. What Is Interaction? In Proceedings of the $2017 \mathrm{CHI}$ Conference on Human Factors in Computing Systems, Association for Computing Machinery, Denver Colorado, CO, USA, 6-11 May 2017; Association for Computing Machinery: New York, NY, USA, 2017; pp. 5040-5052. [CrossRef]

60. Wiberg, M. The Materiality of Interaction; MIT Press: Cambridge, MA, USA, 2018. 
61. Hultink, E.J.; Rijsdijk, S.A. How Today's Consumers Perceive Tomorrow's Smart Products. J. Prod. Innov. Manag. 2009, 26, 24-42.

62. Nicoll, D. Taxonomy of Information Intensive Products; The University of Edinburgh Management School: Edimburgh, Scotland, UK, 1999.

63. Bradshaw, J.M. An Introduction to Software Agents. In Software Agents; AAAI Press: Palo Alto, CA, USA, 1997.

64. Poole, S.; Simon, M. Technological Trends, Product Design and the Environment. Des. Stud. 1997, 18, 237-248. [CrossRef]

65. Norman, D.A.; Nielsen, J. The Definition of User Experience (UX); Nielsen Norman Group: Fremont, CA, USA, 2016 ; Volume 2.

66. Norman, D.A.; Nielsen, J. Gestural Interfaces: A Step Backward in Usability. Interactions 2010, 17, 46-49. [CrossRef]

67. Norman, D.A. Design of Everyday Things; Basic Books: New York, NY, USA, 2013; ISBN 9780465050659.

68. ISO 9241-11:2018; Ergonomics of Human-System Interaction-Part 11: Usability: Definitions and Concepts. Asociación Española de Normalización: Madrid, Spain, 2018. 